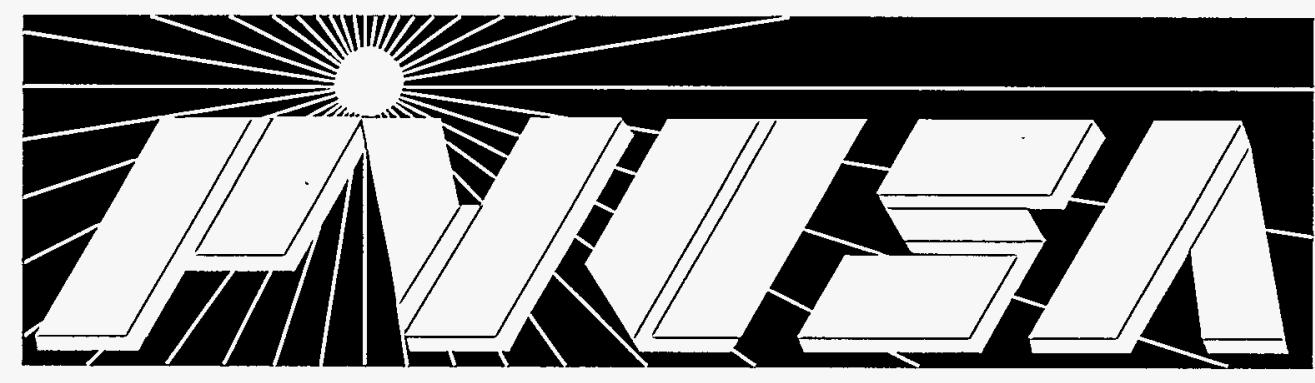

RECH: $D$

NOV 141995

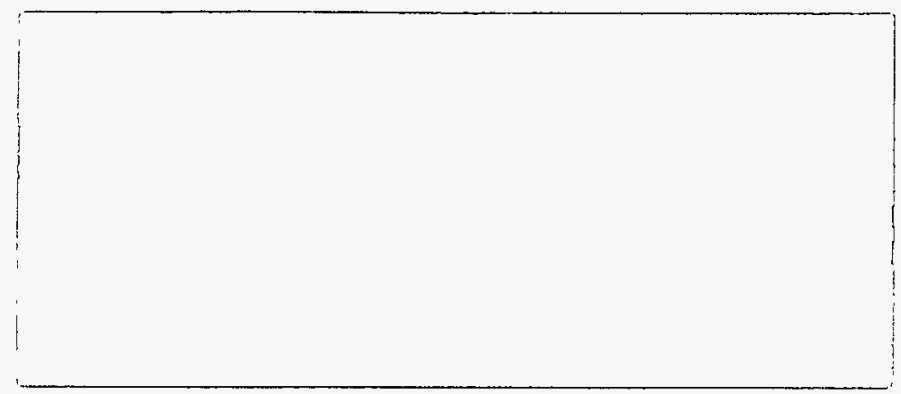

OSTI

Photovoltaics for Utility Scale Applications
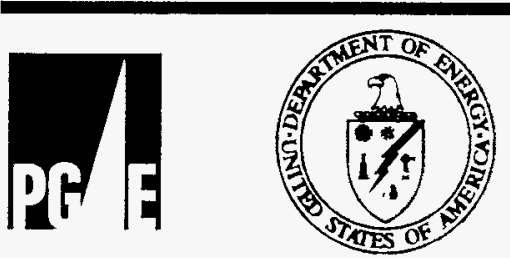

EPRI

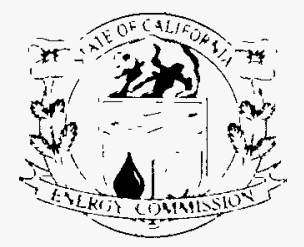



Report Issued: October 26, 1995

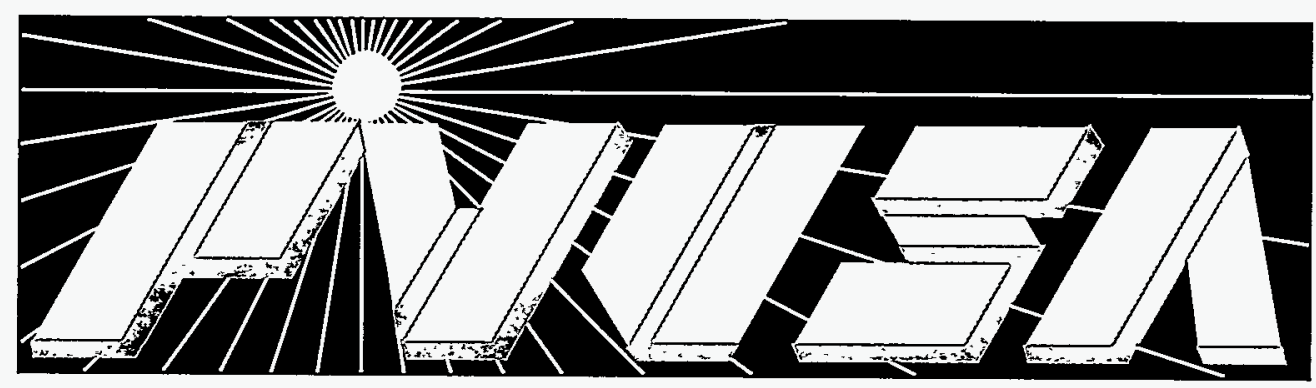

PVUSA Instrumentation and Data

Analysis Techniques

for Photovoltaic Systems

October 1995

Prepared by:

Jeff Newmiller

Paul Hutchinson

Tim Townsend

Chuck Whitaker

ENDECON Engineering

and

PVUSA Project Team

Project Manager:

Brian K. Farmer

PG\&E R\&D Report Number 95-30910000.3 



\title{
PVUSA INSTRUMENTATION AND DATA ANALYSIS TECHNIQUES FOR PHOTOVOLTAIC SYSTEMS
}

\author{
October 1995 \\ Jeff Newmiller \\ Paul Hutchinson \\ Tim Townsend \\ Chuck Whitaker \\ ENDECON Engineering \\ and \\ PVUSA Project Team \\ for

\section{Pacific Gas and Electric Company} \\ Research and Development Department \\ San Ramon, CA 94583 \\ Published October 1995 \\ PREPARED UNDER CONTRACT WITH THE UNITED STATES \\ DEPARTMENT OF ENERGY
}

Cooperative Agreement No. DE-FC04-92AL82993 



\section{DISCLAIMER}

The Pacific Gas and Electric Company (PG\&E) and the United States Government or any agency thereof, or any of their employees, contractors, subcontractors and their employees, (1) make no representation or warranty, expressed or implied; (2) assume no legal liability for damages, including any consequential damages, even if PG\&E and/or the U.S. Government, or any of their representatives, have been advised of the possibility of such damages; or (3) take no responsibility for the accuracy, completeness, or usefulness of any information, apparatus, product, method, or process disclosed, nor do PG\&E or the U.S. Government represent that its use would not infringe the privately held rights of others. Reference herein to any commercial product, process, or service by trade name, trademark, manufacturer, or otherwise, does not constitute or imply its endorsement, recommendation, or favoring by PG\&E or the U.S. Government, any agency thereof, or any of their contractors or subcontractors.

The work disclosed in this report was done with the support of the U.S. Department of Energy, Cooperative Agreement No. DE-FC04-92AL82993. However, any opinions, findings, conclusions, or recommendations expressed herein are those of the author(s) and do not necessarily reflect the views of PG\&E or the U.S. Government, any agency thereof, or any of their contractors or subcontractors.

\section{COPYRIGHT NOTICE}

Copyright 1995, PG\&E, subject to license retained by the U.S. Government under 48 CFR 952.227-75. All other rights reserved. This report and the underlying research were funded and developed for use by PG\&E, members of the PVUSA project, and contributing institutions, including the U.S. Government, the Electric Power Research Institute, and the California Energy Commission. Copies of this report may be obtained for a charge from PG\&E or, if for government use or purposes, from the National Technical Information Service in Springfield, Virginia. Reproduction and/or distribution in any form of this report or any part thereof by anyone other than the U.S. Government is forbidden without express written permission from the copyright owner.

All trademarks referenced in this report are held by their respective owners.

Report Number 95-30910000.3

The Goverment reserves for itself and others acting on its behalf a royalty free, nonexclusive, irrevocable, world-wide license for govermental purposes to publish, distribute, translate, cuplicate, exhibit, and perform any such data copyrighted by the contractor. 


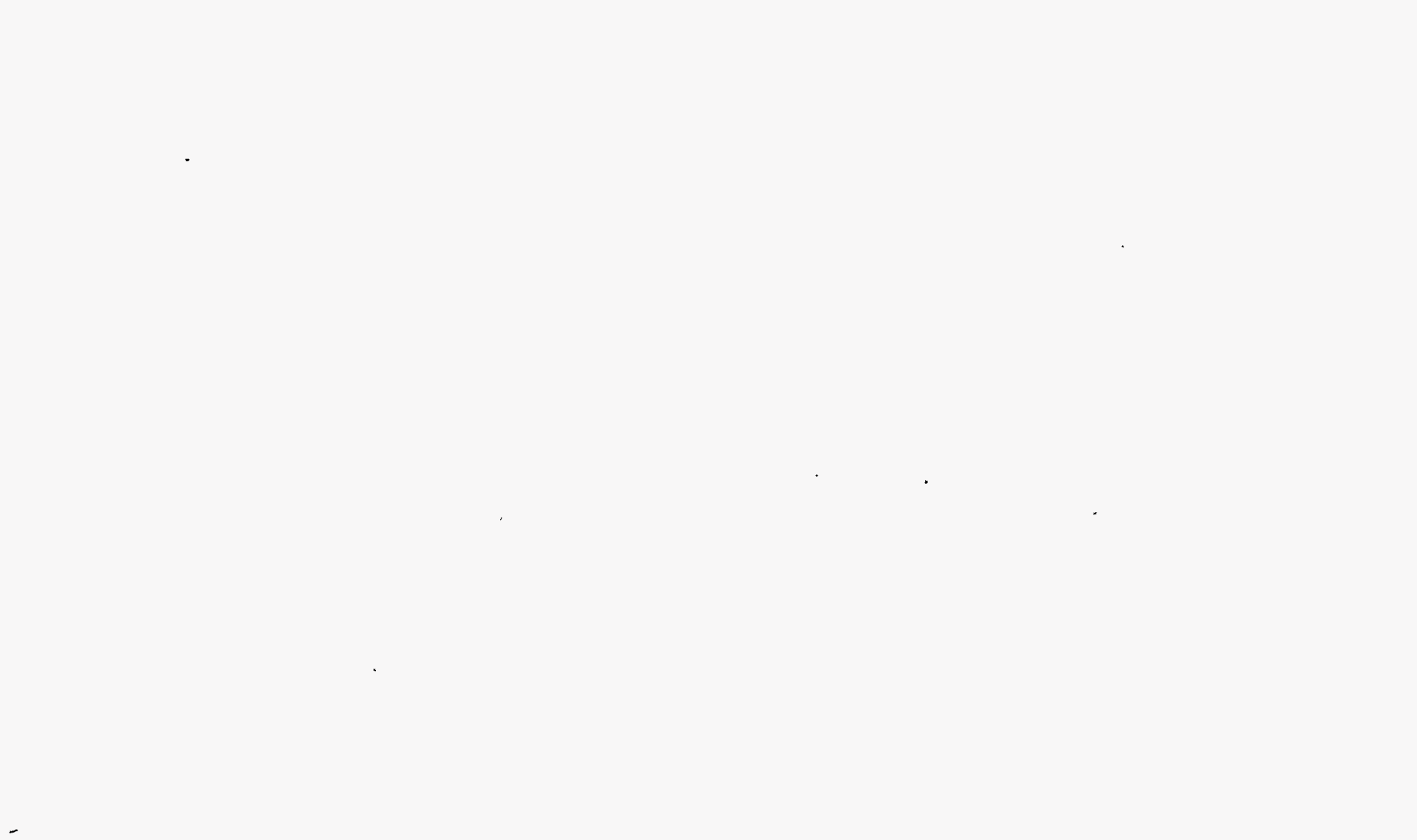




\section{PROJECT PARTICIPANTS}

In addition to the U.S. Department of Energy (including Sandia National Laboratories, the National Renewable Energy Laboratory, and the Jet Propulsion Laboratory), the Electric Power Research Institute, and the California Energy Commission, the support of all of the PVUSA Project members in conducting this research and developing this report is greatly appreciated. Members at the time of publication are

Central and South West Services, Inc.

City of Austin, Texas

New York State Energy Research and Development Authority

Niagara Mohawk Power Corporation

Public Service Company of Colorado

Sacramento Municipal Utility District

Salt River Project

San Diego Gas and Electric

State of Hawaii/Maui Electric Company

U.S. Department of Defense

Virginia Power Company/Commonwealth of Virginia 


\section{ACKNOWLEDGMENTS}

The authors wish to thank the members of PVUSA's Project Team, the Technical Review Committee, and the Steering Committee for their reviews and suggestions. We also wish to thank the many people instrumental in the development and implementation of data acquisition and calibration at PVUSA:

\section{Pacific Gas and Electric Company}

Research and Development: Jim McKenna, Christina Jennings, Lumas Kendrick

Technological and Environmental Services: Richard Raths, Raymond Raths, Steven Rodriguez, Tim Geiger, Dan Kaufman, Keith Herrmann

Meteorological and Ecological Services: Dr. Robert Swanson, Ken Ericsson, Steve Smith, Jeff Murata

Kerman SCADA Development: Quintin Nagramada, Pacifico Joaquin, Joaquin Buendia, Dan Shugar, Howard Wenger

General Construction: Dave Lawton

\section{ENDECON Engineering}

P. Bradley Rosen, Benjamin Valega, Robert Reid, Robert Candelario, Max Parker, Bill Howard

\section{Bechtel Companies}

John Ostrom, Toney Sweeney, Jim Gough, Tony Reyes, Bill Clements, Dawn McKibben, Kerry O'Brien, Dan Shipman

\section{Southwest Technology Development Institute}

Vernon Risser, Steven Durand, Clin Lashway, Cary Lane

We also wish to thank former PVUSA project managers Steve Hester and Tammie Candelario and the current project manager, Brian Farmer, for their questions, guidance, and support and Wendy Ellyn of Wm. Nesbit \& Associates, Inc., for editing this report. 



\begin{abstract}
The Photovoltaics for Utility Scale Applications (PVUSA) project tests two types of PV systems at the main test site in Davis, California: new module technologies fielded as $20-\mathrm{kW}$ Emerging Module Technology (EMT) arrays and more mature technologies fielded as 70- to 500-kW turnkey Utility-Scale (US) systems. PVUSA members have also installed systems in their service areas.

Designed appropriately, data acquisition systems (DASs) can be a convenient and reliable means of assessing system performance, value, and health. Improperly designed, they can be complicated, difficult to use and maintain, and provide data of questionable validity. This report documents PVUSA PV system instrumentation and data analysis techniques and lessons learned. The report is intended to assist utility engineers, PV system designers, and project managers in establishing an objective, then, through a logical series of topics, facilitate selection and design of a DAS to meet the objective. Report sections include Performance Reporting Objectives (including operational versus research DAS), Recommended Measurements, Measurement Techniques, Calibration Issues, and Data Processing and Analysis Techniques. Conclusions and recommendations based on the several years of operation and performance monitoring are offered.
\end{abstract}

The two primary differences between PV systems and conventional power plants are the dispersed and somewhat unpredictable nature of its fuel source (irradiance) and the use of multiple discrete PV modules aggregated to produce power and energy in quantity. In many cases, measuring the appropriate irradiance and dc parameters is key to successful monitoring of PV systems.

This report is one in a series of 1994-1995 PVUSA reports documenting PVUSA lessons learned at the demonstration sites in Davis and Kerman, California. Other topical reports address

- Five-year assessment of EMTs

- Validation of the Kerman 500-kW grid support PV plant benefits

- Construction and safety experience in installing and operating PV systems

- Balance-of-system design and costs

- Procurement, acceptance, and rating practices for PV power plants

- Experience with power conditioning units and power quality 



\section{EXECUTIVE SUMMARY}

Photovoltaics for Utility Scale Applications (PVUSA) is a national cooperative research and development project that has a mission to acquire information through field installation and testing of photovoltaic (PV) technologies in utility-scale applications and to provide the information in a timely manner to utilities and other participants. This report evaluates and documents instrumentation and data analysis techniques used at the PVUSA sites in Davis and Kerman, California, and at PVUSA host sites around the United States.

Data acquisition systems (DASs) monitor parameters of a device or system and provide instantaneous or historical data, which can be used to operate or analyze performance or to troubleshoot. The objective of the DAS portion of the PVUSA program is to

- Establish a credible database for long-term performance trending

- Provide information to utilities interested in developing PV generation systems

- Provide the data needed to evaluate and model PV system performance in a utility setting

- Determine the minimum number of parameters necessary to characterize system performance

- Develop procedures for using Supervisory Control and Data Acquisition (SCADA) on PV systems

Data acquisition for PVUSA requires a broad spectrum of equipment, software, and expertise. Evaluation of PV system performance requires computation of multiple measures based upon data streams that are generated by several pieces of sophisticated equipment. The research nature of this project requires a high level of detailed monitoring and therefore a large number of monitoring channels. At the other end of the spectrum are commercial and residential PV systems, which may be adequately monitored by simple revenue metering. In between these two extremes, PVUSA has identified the five parameters needed to adequately determine system functionality. These parameters, shown in Table ES-1, may be displayed in real time or stored for historical analysis. 
Table ES-1

Recommended Basic Measurement Set

\begin{tabular}{||l|l|l||}
\hline Parameter & Units & Derived Performance Measure \\
\hline Plane-of-array irradiance & $\mathrm{W} / \mathrm{m}^{2}$ & $\begin{array}{l}\text { Input power and energy, array and } \\
\text { system efficiency, performance index }\end{array}$ \\
\hline Real ac power & $\mathrm{kWac}$ & $\begin{array}{l}\text { Peak output power, output energy, } \\
\text { system availability, capacity factor, } \\
\text { PCU and system efficiency, } \\
\text { performance index }\end{array}$ \\
\hline Array dc bus voltages & $\mathrm{Vdc}$ & $\begin{array}{l}\text { dc power and energy, array efficiency, } \\
\text { voltage imbalance }\end{array}$ \\
\hline Array dc bus currents & $\mathrm{Adc}$ & $\begin{array}{l}\text { dc power and energy, array efficiency, } \\
\text { current imbalance }\end{array}$ \\
\hline Module back temperature & ${ }^{\circ} \mathrm{C}$ & Performance index \\
\hline \hline
\end{tabular}

\section{KEY FINDINGS}

PVUSA has determined that four topics must be addressed to ensure a successfully implemented DAS:

- Performance Reporting Objectives

- Measurement Philosophy and Techniques

- Calibration Procedures and Maintenance Issues

- Data Processing and Analysis Techniques

These topics must be analyzed to answer the following questions: Why are we monitoring this PV system? What parameters do we need to monitor and how? How will we ensure that the data are accurate? What will we do with the data once collected?

\section{Performance Reporting Objectives}

"Why are we monitoring this PV system?"

All too many data acquisition systems have been installed without careful thought as to the real needs for the data being collected. With ever increasing computer power and capacity a common approach is to monitor every conceivable parameter. However, data quality checking can only be partially automated. As a result, the data must be manually reviewed on a regular basis to ensure a quality data set. Large numbers of data channels and high storage rates will result in a burdensome quantity of data processing and significant cost for potentially unnecessary data. An immense quantity of data can make an otherwise mundane analysis task unapproachable.

Conversely, even PVUSA's rather extensive data set can leave pieces missing from the puzzle. Fivesecond scans-let alone the 10-minute averages stored by PVUSA-are not sufficient to measure 
electrical transient events. A string imbalance may not show up in a measurement of a monopole that consists of multiple strings until the imbalance is nearly catastrophic.

The intent of operating the PV system, the reporting objectives, and the audience for those reports should be defined. There are fundamental differences between data collection approaches used for performance evaluation and comparison versus those used for system control. In the former case the important issue is a complete historical data set; in the latter case up-to-date real-time information is critical.

\section{Measurement Philosophy and Techniques}

"What parameters do we need to monitor, and how?"

The basic monitoring parameters were provided in Table ES-1. These parameters describe the minimum set of performance measures necessary to evaluate basic system performance. In addition, it is important to record the date and time of day to allow merging and comparison of data from different systems; to calculate sun position; and, for tracking systems, to calculate expected array position. Depending on the needs of the project, other parameters such as more-detailed array voltages and current, tracker position, component temperature, PCU status signals, and possibly non-PV parameters such as building load and feeder voltage may be necessary.

For measuring the desired quantities, there is a wide variety of devices and techniques with various accuracies and associated cost. Where practical, it is best to use devices familiar to the operations and maintenance (O\&M) personnel. Standard utility ac and dc metering (current and potential transformers tied to $\pm 1 \mathrm{~mA}$ output $\mathrm{I} / \mathrm{V} / \mathrm{kW}$ transducers, voltage dividers, current shunts, etc.) is adequate for most applications 1 . Thermocouples and RTDs are typically used for temperature measurements. Traditional meteorological equipment is used to measure common climatic conditions.

There are some PV-specific issues that need to be considered. Irradiance (sun intensity in $\mathrm{kW} / \mathrm{m}^{2}$ ) measurements utilize equipment that has somewhat peculiar characteristics, relatively low accuracy, and specialized calibration requirements. PV array dc current measurements are often made in a high-voltage leg of a center ground array. When a current shunt or other nonisolated current measuring device is used, the sensor output should be isolated from the measurement device because of the high common mode voltage present.

As mentioned earlier, data recording intervals trade off quantity of data for resolution of transient events. Averages of not greater than 1 hour are sufficient to capture power-related information. Samples should be taken every 10 seconds or less to address solar transients.

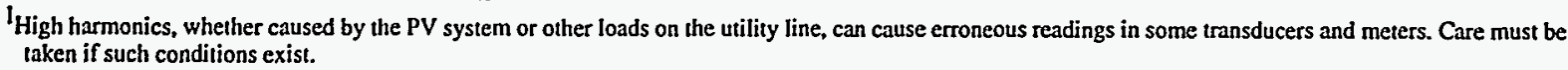




\section{Calibration Procedures and Maintenance Issues}

\section{"How will we ensure that the data are accurate?"}

When determining which parameters to measure and how to measure them, it is important to consider calibration requirements and procedures. While some components-such as ac instrumentation transformers and transducers-may only need calibration verification every few years, pyranometers, the devices that measure sun intensity, need annual calibration and may need to be cleaned every few days. This frequency of maintenance may not be feasible in remote, unmanned locations, so a trade-off between data accuracy and maintenance level must be made.

\section{Data Processing and Analysis Techniques}

"What will we do with the data once collected?"

The mechanics of data processing should be chosen based on the answers to this and the preceding questions. Options for data processing and analysis range from calculating the customer's bill (or check!), to displaying key performance and status values on an operator's console or doing an in-depth analysis of the performance characteristics of individual components.

If the purpose of monitoring the system is for plant operations and determining and controlling plant output, existing utility SCADA and data processing equipment and techniques should be employed. In a situation where long-term plant or component performance is to be evaluated, SCADA may not be the best choice.

PVUSA has found that long-term storage and analysis are best served by a relational database containing the performance data. In addition to providing a convenient environment for data screening, a properly designed database can simplify both automated reporting and ad hoc analyses.

O\&M information in the same or a separate database is critical to future analysis of the data, as is documentation of any condition that would affect the analysis of the data. An example of the latter is.a situation where the array is significantly or partially covered by snow but the pyranometer has a clear view of the sun. Without any additional documentation, the high irradiance and low or no array output would suggest an array or power conditioning unit problem.

Most utility measures for conventional power plants-voltage, current, power, energy, efficiency, capacity factor, availability-can be applied to PV. However, certain characteristics, such as the timevarying nature of the solar fuel, must be accounted for by modifying the definition of a measure, modifying the interpretation of a measure, or developing new measures. PVUSA has done all of these, 
including instituting the use of the Performance Index (PI), a parameter that compares the actual system output (power or energy) to expected output. The PI has proven to be useful for quickly assessing the health and status of a PV system.

Conclusions

Data analysts -research engineers, maintenance technicians, or system operators -often find that they have too much data to deal with but not enough to perform the desired analysis. Proper planning on the part of the DAS designer will help to minimize the amount of data collected and maximize its usefulness. Combined with the appropriate hardware, calibration and maintenance methods, and data processing approach, data acquisition will provide the information necessary to operate or analyze a PV system.

Project Manager

Research Director

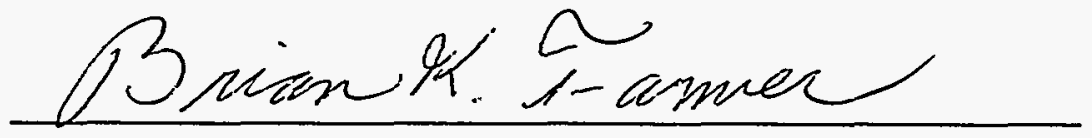

Brian K. Farmer

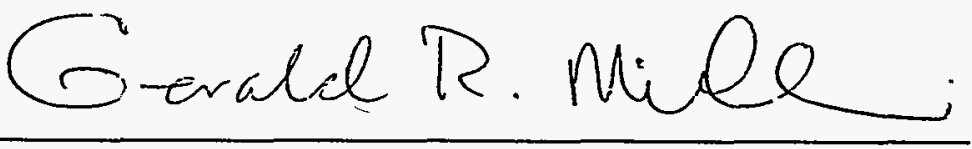

Gerald R. Miller

Report Number 95-30910000.3

ES-5 



\section{CONTENTS}

1 INTRODUCTION

REPORT OBJECTIVES .

PVUSA BACKGROUND

1-1

DAS BACKGROUND

REPORT ORGANIZATION

2 PERFORMANCE REPORTING OBJECTIVES .................................. $2-1$

BACKGROUND ..................................................................... $2-1$

PERFORMANCE MEASURES ......................................................... 2-2

REAL-TIME VERSUS HISTORICAL DATA PRESENTATION ................... $\quad 2-6$

3 RECOMMENDED MEASUREMENTS …............................................

MINIMAL DAS .................................................................................

BASIC DAS..................................................................... $3-1$

REMOTE OPERATION DAS ......................................................... $3-4$

EXAMPLE DATA STORAGE FORMATS ........................................ $3-4$

4 MEASUREMENT TECHNIQUES .................................................. 4-1

BACKGROUND ................................................................. 4-1

SENSORS ............................................................................. 4-1

SIGNAL CONDITIONING .......................................................... 4-13

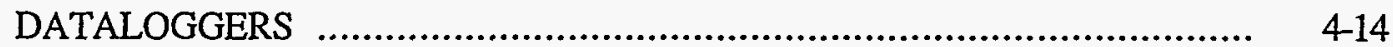

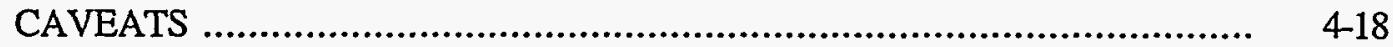

5 CALIBRATION ISSUES ............................................................ $5-1$

BACKGROUND ................................................................... $5-1$

SENSORS .................................................................................. 5

SIGNAL CONDITIONING ...................................................... $5-9$

DATALOGGERS ......................................................................

6 DATA PROCESSING AND ANALYSIS TECHNIQUES .......................... $6-1$

EQUIPMENT ........................................................................ $6-1$

SOFTWARE ............................................................................

DATA ORGANIZATION ........................................................... $6-5$

ALGORITHMS ................................................................... $6-8$

7 CONCLUSIONS AND RECOMMENDATIONS ..................................... $7-1$

CONCLUSIONS ................................................................... $7-1$

RECOMMENDATIONS ............................................................

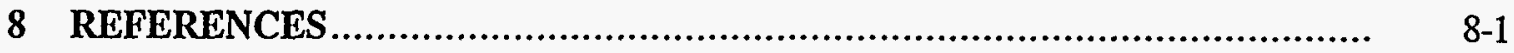

Appendix A:

GLOSSARY ............................................................... A-1

Appendix B:

RADIOMETER SUPPLIERS ............................................... B-1 



\section{FIGURES}

Figure Page

1-1 Diagram of typical grid-connected PV power plant..................................... 1-3

4-1 Example voltage divider schematic ...................................................... 4-2

5-1 Calibration factor versus azimuth angle for precision spectral pyranometer ............. 5-5

6-1 PVUSA Davis DAS hardware.......................................................... $6-1$

6-2 Typical single-system real-time display ............................................... $6-4$ 



\section{TABLES}

Table

Page

3-1 Recommended Basic Measurement Set

3-3

3-2- System Performance Measures Available in Basic DAS............................. 3-3

3-3 Typical PVUSA EMT System Data File Format .................................... $3-5$

3-4 Typical PVUSA US System Data File Format ......................................... 3-7

4-1 Comparison of Temperature Sensors .................................................... 4. 4

4-2 Potential Instrument Interfacing Requirements ....................................... 4-17 



\section{Section 1 \\ INTRODUCTION}

This section states the objectives of this report, briefly describes the Photovoltaics for Utility Scale Applications (PVUSA) project, provides background on data acquisition systems (DASs), and summarizes the report organization.

\section{REPORT OBJECTIVES}

This document discusses the key issues relevant to monitoring the performance of grid-connected photovoltaic (PV) power plants, with particular reference to lessons learned in the course of monitoring the systems installed by PVUSA at sites in Davis and Kerman, California.

Utility interest in monitoring and control of PV systems is increasing as PV systems with greater impact on the utility distribution network are installed worldwide. National programs such as Utility Photovoltaic Group's (UPVG's) TEAM-UP have varying requirements for performance information. Utilities are generally unaware of the appropriate parameters and measurement technology necessary to monitor and control a PV system. The objective of this report is to provide an overview of PVUSA's experience with these issues so that the techniques used and the lessons learned may be applied to future PV projects.

The target audience for this report is project management and technical personnel considering PV plant construction and ownership and those interested in using data acquisition to monitor PV systems. The report focuses on the traditional DAS, based upon Campbell Scientific, Inc. (CSI) dataloggers, and provides insight into the use of utility standard supervisory control and data acquisition (SCADA).

This document may be used to

- Determine the appropriate type and number of parameters to monitor

- Select appropriate monitoring equipment

- Develop system performance tables and plots for summarizing long-term and real-time PV system performance

- Determine which performance measures are most appropriate for an application

- Develop a calibration schedule and procedures 
Complementary reports and conference papers containing other aspects of PV data acquisition and reporting are available. Performance and special tests are presented in the PVUSA Progress Reports (PVUSA Project Team 1989-1990, 1991, 1992, 1993, 1994). Additional information is contained in PVUSA reports on system procurement, power conditioning units (PCUs), balance-of-system (BOS) costs, construction and safety, and the operation and maintenance (O\&M) of specific PVUSA systems.

\section{PVUSA BACKGROUND}

PVUSA is a national cooperative research and development project that has a mission to acquire information through field installation and testing of PV technologies in utility-scale applications and to provide the information in a timely manner to utilities and other participants, facilitating informed decisions. To achieve its mission, PVUSA has the following five objectives:

1. Evaluate the performance, reliability, and cost of promising PV modules and BOS components side by side at a single location.

2. Assess PV system O\&M in a utility setting.

3. Compare PV technologies in diverse geographic areas.

4. Provide utilities in the United States with hands-on experience in designing, procuring, and operating PV systems.

5. Document and disseminate knowledge gained from the project.

The project consists of emerging module technology (EMT) arrays and utility-scale (US) systems. EMTs are state-of-the-art PV module technologies that had not been previously field-tested. The nominal $20-\mathrm{kW}$ size of the EMT arrays was selected to demonstrate ease of manufacture and allow a statistically credible evaluation, while minimizing the risks associated with a new technology.

US systems are vendor-optimized turnkey PV systems that use mature module technologies and have the potential to produce low-cost energy for utility applications. The US systems (including host utility systems), ranging from $20 \mathrm{~kW}$ to $500 \mathrm{~kW}$, capture some economies of scale and provide important data on constructability, costs, system protection requirements, performance, reliability, O\&M, grid interaction, safety, and lifetime.

\section{DAS BACKGROUND}

A diagram of a typical grid-connected PV power plant is shown in Figure 1-1. Solar power incident on the PV array generates dc power, which is delivered to the PCU for conversion to ac power, which is in 


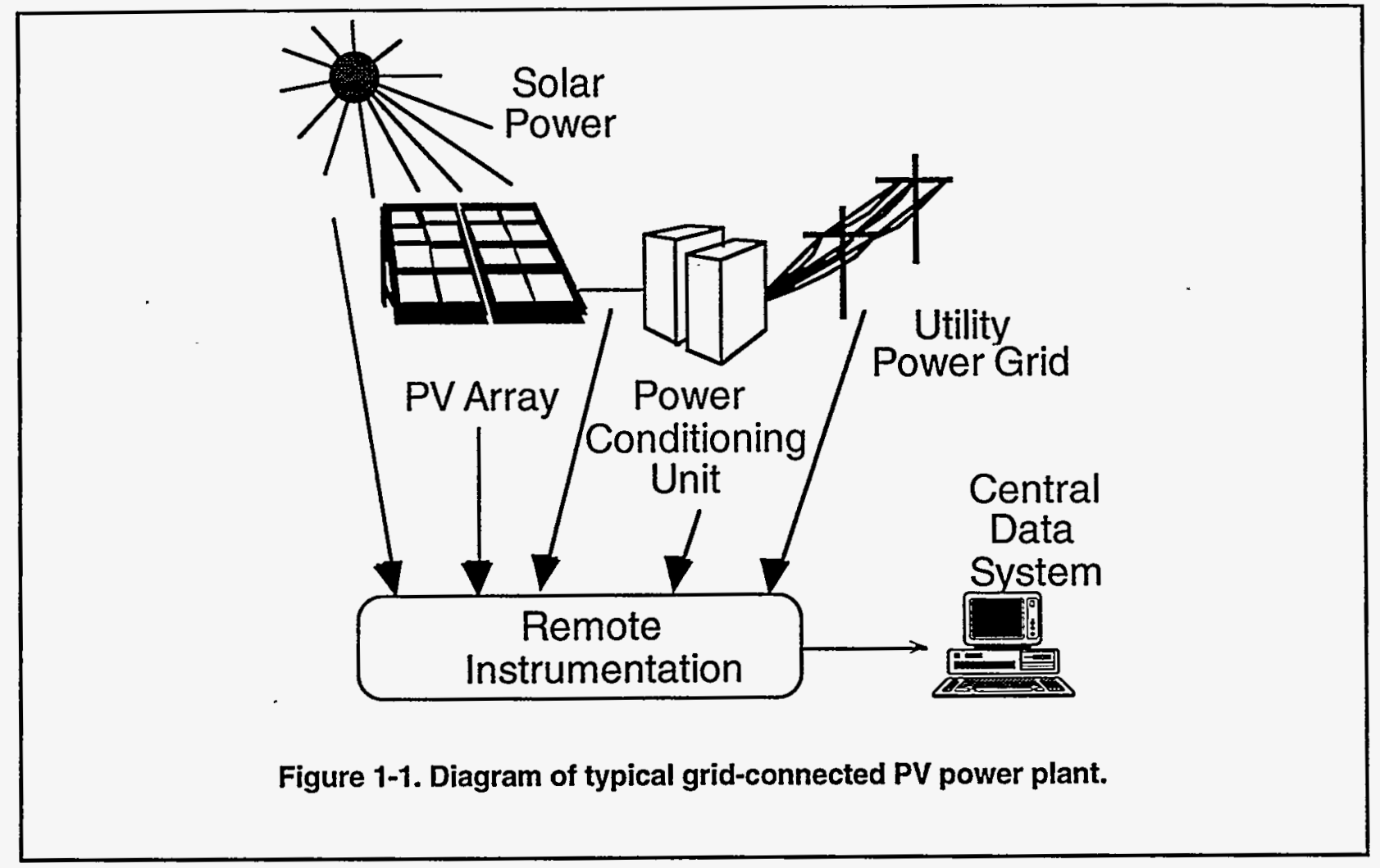

turn delivered to the utility power grid. The DAS consists of the remote instrumentation and an optional central data collection and processing system.

Designing, installing, and operating an appropriate DAS requires decisions about what system information is necessary, how the information will be used, what parameters are to be measured, and how they are to be measured. In general, monitoring of a grid-connected PV power plant may involve measuring the inputs (solar power), operational status, and outputs (ac power). The choice of exactly which parameters to monitor depends strongly on the extent of the performance reporting and maintenance planned for the PV system.

Monitoring requirements will depend on anticipated system reliability and application. The reliability of prototype components will not generally be as high as for commercial mass-produced components. Additional monitoring will be warranted, either to provide diagnostic information in case of problems or to characterize the component's performance when that is the purpose of the project. A mission-critical application, such as a distribution support system like Kerman, will have a higher degree of monitoring for maintenance diagnostics than a less critical application like a roof-mounted demand-side management system. A research and test installation (such as PVUSA) where complete records of system performance 
are required to document testing and operation will require the most extensive monitoring. Utility-style revenue metering is sufficient for revenue-generating applications such as the Sacramento Municipal Utility District's (SMUD's) residential PV installations.

Data acquisition for PVUSA is centered at the main project site in Davis, California. The Davis system consists of a network of CSI dataloggers-one for each PV system, one for the solar/weather instruments, and one for utility grid monitoring. Monitoring at most other PVUSA sites is performed by remote CSI dataloggers that communicate with the Davis site via a telephone modem.

The DAS monitors ac and dc voltage, current, and power; neutral current; daily ac $\mathrm{kWh}$; module and ambient temperature; plane-of-array (POA), horizontal, direct normal, and global normal irradiance; wind speed and direction; and rainfall. The DAS also monitors several status signals on each PCU, including on/off status, error off, recycle, and a smoke alarm, and can control system operation.

Some of the lessons learned in the course of designing, installing, and maintaining the PVUSA DAS are only relevant to research applications; however, these lessons provide insight into less comprehensive systems as well.

\section{REPORT ORGANIZATION}

This report describes lessons learned in the course of monitoring PV systems at PVUSA Davis, PVUSA Kerman, and host sites. It is divided into the following sections:

This section (Section 1) states the report objectives, briefly describes the PVUSA project, provides background on DAS, and summarizes the report organization.

Section 2 discusses the detailed system analysis and performance reporting objectives that were the primary basis for determining which measurements would be needed in the PVUSA DAS.

Section 3 describes the advantages and disadvantages of measuring various parameters in PV systems with minimal DAS, basic DAS, and remote operation DAS.

Section 4 describes the measurement techniques and components used at PVUSA.

Section 5 discusses calibration requirements and methods. 
Section 6 describes the data processing hardware and software of the PVUSA DAS and how they were used to compute the performance measures described in Section 2.

Section 7 presents conclusions and lessons learned.

Section 8 lists referenced publications.

Appendix A contains a glossary.

Appendix B contains a list of radiometer suppliers. 

Section 2

\section{PERFORMANCE REPORTING OBJECTIVES}

This section discusses the detailed system analysis and performance reporting objectives that were the primary basis for determining which measurements would be needed in the PVUSA DAS. It describes the performance measures appropriate for evaluation of PV power plants, including power production, energy production, efficiency, daytime system availability, capacity factor, and Performance Index (PI). It also explores the advantages and disadvantages of real-time and historical data presentation.

\section{BACKGROUND}

Performance reporting objectives must take into account what information is needed from a PV monitoring system and when it should be reported. What information is needed may include both direct and composite measurements designed to emphasize particular characteristics of PV system operation. Reporting frequency may emphasize speed of display for effective operations or continuity of long-term (archival) data collection for historical evaluation.

Different PV systems are designed to emphasize particular characteristics; thus, what needs to be reported will depend on the application. For all of its PV systems, PVUSA monitors essentially the same parameters and computes both array and system performance. This approach provides a full spectrum of measures which identify weaknesses and failures in the DAS and PV systems and, more importantly, characterize the performance of different systems at one location and similar systems at different locations.

The frequency with which performance measures are reported also depends on the application. Some systems, such as residential or commercial rooftop PV or cathodic protection, may only require performance monitoring on a monthly or yearly basis. PV systems requiring interactive monitoring and control must present measurements to operators every second or minute; in these cases, the economic cost of downtime may be sufficient to justify the cost of the operator and interactive control system. In the case of PVUSA research, quality data are desired which require a data rate as fast as the dataloggers can reliably sample (5 seconds). Dataloggers average the 5-second samples over 10 minutes for archival purposes. Real-time display of the Davis site status and operating performance are updated on an average of once per minute, and reports summarize performance at weekly, monthly, quarterly, and yearly intervals.

SCADA systems typically provide the operator some degree of interactive system control and can inform the operator of at least some portion of the power system's current status (on or off, power level, 
operating mode, etc.). For smaller power systems in noncritical applications, the SCADA system may be nonexistent, or simply a panel with lights and switches next to the PCU. Larger power systems or collections of systems typically have a computerized communication network with a central operator console that displays the status of individual systems. Computerized SCADA systems can be designed to optimize either real-time interaction or archival data record keeping.

\section{PERFORMANCE MEASURES}

The performance measures appropriate for the evaluation of PV power plants are similar to those applied to conventionally fueled power plants. However, the variability of the fuel source for PV plants complicates the calculation and interpretation of these measures.

\section{Power Production}

While the primary purpose of PV power plants is to produce power, use of power output as a direct assessment of system performance is complicated by its dependence on a variable fuel source. The power output of a conventional power plant is normally. subject to some level of control (even if only to produce a fixed power output), so the actual output may be directly compared with the desired output. The power production of PV power plants, on the other hand, depends on the available sunlight and cell temperature, and to a lesser extent on a number of additional environmental parameters, such as wind speed, wind direction, ground reflection, sky condition, time of year, etc. These environmental factors significantly reduce the utility of evaluations that rely on direct examination of a PV power plant's power output alone when performing maintenance and diagnostics.

The variation in PV plant power output over time also complicates the evaluation of a PV system. Many samples may be required to accurately represent the power output over a given time interval; these samples must be condensed before presentation so as not to overwhelm the person evaluating the PV system.

One way to reduce the data is to extract the maximum power measured during a time interval. This can provide a usable indication of how well the PV system is performing if there is clear weather during the peak irradiance period of the interval. However, if the weather is not clear, the power production will be unpredictable, and the maximum power value will be less useful in evaluating overall operation.

Another way to reduce the data is to average the power production over a time interval. This is not usually done for long intervals because it provides the same information as the energy production measure does (differing only by a scaling factor). However, for intervals of less than an hour, power 
averaging can be used to capture the significant (in terms of energy) variations in power for historical performance recording while reducing the storage requirements of the data collection system.

The additional performance measures described below are designed to address difficulties with calculation and interpretation by either aggregating the data over time or comparing measurements from various parts of the system, or both.

\section{Energy Production}

Energy production is obtained from measurements of power using

$$
E_{1-2}=\int_{t_{1}}^{t_{2}} P d t
$$

where $P$ is the power flowing at the point of measurement and $t_{1}$ and $t_{2}$ are the beginning and end of a time interval.

In its raw form, this equation computes the net energy transfer. For example, if $10 \mathrm{~kW}$ flows into a system (consumption) for 1 hour and a constant 10-kW power flows out of the system (production) for 3 hours, this equation will compute $20 \mathrm{kWh}$ of net energy production. In a utility environment the energy flows into and out of a power plant may be computed separately to accommodate standard billing practices.

Energy is the basic unit of revenue for electric utilities, so this measure of performance is of primary importance to PVUSA, particularly at the point where the power is delivered to the utility power grid. However, PVUSA also computes the dc energy delivered by the PV array and the solar energy per unit area as seen by the PV array (insolation). These measures are used for assessing component performance and for comparison when diagnosing system energy production shortfalls.

Typical monthly values of ac energy, dc energy, and insolation for a 20-kW fixed-tilt flat plate system at Davis are on the order of $2000 \mathrm{kWhac}, 2100 \mathrm{kWhdc}$, and $200 \mathrm{kWh} / \mathrm{m}^{2}$, respectively.

\section{Efficiency}

Energy conversion efficiency is defined as

$$
\eta_{1-2}=\frac{E_{u, 1-2}}{E_{i, 1-2}}
$$


where $E_{u, 1-2}$ is the useful energy output of some system and $E_{i, 1-2}$ is the total energy input to that system, both over the interval of time $t_{1}$ to $t_{2}$. The system can be defined as the PV module array, the PCU, or the entire power plant. When $t_{1}$ approaches $t_{2}$, this equation reduces to the instantaneous (power) efficiency.

Energy conversion efficiency measure is a useful parameter for describing advancements made in a particular technology and for comparing one technology with another. This measure is used at PVUSA for comparison with manufacturer's data, for evaluating diurnal and seasonal changes, and as a measure of component degradation. Efficiency is computed for the PV arrays, PCUs, and system (from sunlight input to ac output). Typically the PV array efficiency is between 2 and $14 \%$, while the long-term PCU efficiency ranges from 85 to $96 \%$. The overall system efficiency is equal to the product of the PV array efficiency and the PCU efficiency.

\section{Daytime System Availability}

System availability (SA) is typically defined by the equation

$$
S A_{1-2}=\frac{\sum_{i} \Psi_{i} \cdot \Delta t_{i}}{\sum_{i} \Delta t_{i}}
$$

where, in a reporting interval from time $t_{1}$ to $t_{2}, \Delta t_{i}$ is the $i$ th subinterval during which the system was expected to be available (for example, the daylight hours of a day), and $\psi_{i}$ is the fraction of the system that was available during that same time interval. Understanding when the system is expected to operate and what portions must operate is critical to interpreting this statistic. PVUSA assumes that gridconnected PV systems should deliver some ac power to the grid during the daytime in order to be counted as operational. For example, a PV system with two inverters, one of which is off-line from midnight until solar noon on a clear day, should have an SA of $75 \%$ for that day. Nighttime is excluded as a scheduled outage, but extremely overcast weather will penalize availability in a manner similar to an unscheduled outage.

$\mathrm{SA}$ is a common statistic calculated on a regular basis for conventional power plants. Its intent is to describe how often the system is available to generate power; that is, it indicates system reliability. Note that, in general, even if the system is not producing power it can be available.

For most PV systems SA is about $80 \%$ under normal conditions (i.e., no broken components, clear weather) because tare losses prevent the system from producing net power when the irradiance is low (e.g., sunrise/sunset, heavy overcast weather). However, the energy lost at sunrise and sunset is typically 
small (less than $2 \%$ of the total daily insolation) so the SA of $80 \%$ results in a conservative estimate of system reliability.

\section{Capacity Factor}

Capacity factor $(\mathrm{CF})$ is defined by the equation

$$
C F_{1-2}=\frac{E_{0,1-2}}{P_{\text {rated }}\left(t_{2}-t_{1}\right)}
$$

where $t_{1}$ and $t_{2}$ are the beginning and end times for the interval of interest, $P_{\text {rated }}$ is the rated system output, and $E_{o, 1-2}$ is the ac (or dc if $P_{\text {rated }}$ is dc) energy produced during that interval. Note that nighttime is not excluded in this calculation. This measure is affected by system downtime (low system availabilities), weather (sunlight availability), and time of year (day length). Like SA, CF can also be calculated for various periods, such as day only and peak demand periods.

PVUSA uses this measure to indicate how a PV system's average power compares with its rated power at PVUSA Test Conditions (PTC) ${ }^{1}$. Typical short-term values may range from $10 \%$ in the winter to more than $30 \%$ in the summer, with an annual average of about $20 \%$. For comparison, a $30^{\circ}$ fixed-tilt system operating at its rated value at solar noon (when the incident solar power is greatest) on March 21 (when the day length is 12 hours) would have a daily CF of about $29 \%$. If the system tracked the sun, operated under better conditions than the rating conditions (higher irradiance, lower temperature), or the day length was longer, this value would be improved. In practice, however, operating conditions are usually worse than the rating conditions, which explains the $20 \%$ annual average $C F$ quoted above.

\section{Performance Index}

Performance Index (PI) is defined as the ratio of actual power or energy output to the expected power or energy output [1]. The expected output is equal to the rated output multiplied by a series of adjustment factors. As needed for a given application, the adjustment factors account for the expected change in output power due to irradiance and temperature variation, soiling, long-term degradation, BOS losses, or other quantifiable losses. The various adjustment factors are assumed to equal 1.0 if their effects are unknown.

For diagnostic purposes, PVUSA's real-time monitoring software compares the instantaneous PI to a chosen minimum acceptable threshold of $90 \%$ (i.e., $10 \%$ less than rated operation). This threshold allows for measurement uncertainty on the order of $3 \%$ and for minor soiling and BOS losses. PI levels of $90 \%$ 1 PTC are defined as $1,000 \mathrm{~W} / \mathrm{m}^{2}$ plane-of-array radiance $\left(850 \mathrm{~W} / \mathrm{m}^{2}\right.$ direct normal irradiance for concentrators $), 20^{\circ} \mathrm{C}$ air temperature, and $1 \mathrm{~m} / \mathrm{s}$ wind speed at
$10 \mathrm{~m}$ height. 
or less can be triggered by heavy soiling, partial system outages, or other smaller loss mechanisms such as poor tracking or interrow shading.

For instantaneous evaluation (i.e., for a real-time display), the resulting equation used by PVUSA is

$$
P I=\frac{P_{o} H_{P T C}}{P_{\text {rating }} H_{i}\left(1+\beta\left(T_{\text {mod }}-T_{\text {mod, PTC }}\right)\right)}
$$

where $P_{o}$ is the actual output power, $P_{\text {rating }}$ is the rated system output, $H_{P T C}$ is the irradiance defined for $P T C, H_{i}$ is the actual irradiance incident on the array, $T_{\text {nod }}$ is the module temperature, $T_{\text {nod,PTC }}$ is the module temperature under PTC, and $\beta$ is the temperature coefficient of peak power for the modules.

For evaluating the performance index over an interval of time, the equation is

$$
P I_{1-2}=\frac{E_{o, 1-2} H_{P T C}}{P_{\text {rating }} G_{i, 1-2}\left(1+\beta\left(\bar{T}_{\text {mod }}-T_{\text {mod, } P T C}\right)\right)}
$$

where $E_{0,1-2}$ is the actual output energy and $G_{i, 1-2}$ is the actual insolation incident on the array during the interval $t_{1}$ to $t_{2}$ and $\overline{T_{\text {mod }}}$ is the power-weighted average module temperature, defined by

$$
\overline{T_{\text {mod }}}=\frac{\int_{t_{1}}^{t_{2}} P_{o} \cdot T_{\text {mod }} d t}{E_{o .1-2}}
$$

The PI measure can be interpreted as a modified CF insensitive to the variations in sunlight availability and other uncontrollable ambient conditions. The effects of soiling, spectral variations, and partial and full outages are accounted for in a single measure. When evaluated over weekly or monthly intervals, it is useful in identifying minor (5-20\%) system performance degradations that would otherwise be hidden by variations in sunlight availability or temperature variation. Expected values are $85-95 \%$, though values can reach $100 \%$.

Since its recent incorporation into the PVUSA DAS, the PI has proven to be a useful measure for monitoring the output of numerous systems of varying size. It is recommended for identifying both immediate failures and longer-term drop-offs in performance.

\section{REAL-TIME VERSUS HISTORICAL DATA PRESENTATION}

Distributed computerized DASs are typically designed to optimize either the speed of display or the continuity of long-term data collection, but not both. This choice is necessary because, when communication errors occur, the system must choose whether to resend the data that did not get transferred correctly or simply to send the most recently collected data. Resending old data maintains 
continuity of the archival data, but if those data are displayed, the operator sees (and makes decisions based on) outdated data. Additional storage capacity is also required to support transmission of a continuous archival data stream in spite of communication failures.

Communication errors must be expected to occur in the normal course of operations. Anything from electrical noise due to power switching to a software failure on the data display or archiving computer can disrupt communications. Many real-time communication systems balance the need for current data and reliable data transfer by allowing for a few retransmissions before discarding the old data values.

\section{Data Presentation at Davis}

At PVUSA Davis, both real-time and archival data are needed continuously. However, a continuous record of archival data is significantly more important than real-time data. To meet both of these needs, the DAS reduces the amount of archival data by averaging it at the point of collection (the datalogger) at 10-minute intervals and transferring the reduced data to the central display and collection computer at 20minute (or greater) intervals. Between archival data transfers, real-time data are transferred to the central computer. This approach results in 5-10 seconds of missed real-time data for each system monitored every 20 minutes. The communications protocol built into the remote dataloggers requires 4-8 seconds per datalogger to collect the real-time data, and communication with the dataloggers is multiplexed through a single communication channel. With these constraints, the update rate at the display console for any specific real-time data is roughly 50 seconds for 150 channels collected from 11 dataloggers. The collection of archival data therefore delays the real-time data collection by about 10-20\% during every 20-minute interval.

Reducing the amount of archival data at the point of collection also makes best use of the datalogger memory for handling collection computer downtime. In the PVUSA DAS the dataloggers are equipped with enough memory to keep at least 3 days of data, so that collection computer hardware failures occurring on Saturday can be addressed on Monday with no loss of archival data.

\section{Data Presentation at Kerman}

The Kerman PV power plant was designed to operate via a conventional SCADA Remote Terminal Unit (RTU) interface by PG\&E substation and distribution operations personnel. PG\&E's Research and Development Department installed a local console to allow on- and off-site monitoring, archival data collection, and remote downloading. Both the Westronic RTU and the commercially available RealFlex monitoring package selected for this project were optimized for operator interaction and real-time display. The RealFlex software was noticeably strained by its application to both stand-alone operation and 
archival data collection. This strain appeared in poor management of disk space, the limitations of the averaging and communications software, and poor system reliability.

In contrast to the "system under test without full-time operators" philosophy used by PVUSA, conventional utility SCADA systems are designed first and foremost to inform the operator and allow power system control. These SCADA systems usually do not provide distributed storage capability because off-line data processing is not a high priority. Where the data are critical to the operation of the system, the utility will ordinarily support operators on site and/or provide redundant communication systems.

While the use of existing utility-standard SCADA hardware and software for PV should be encouraged to ease integration of PV into a utility's dispatchable generation mix, the suitability of these systems for long-term or specific test data analysis purposes should be evaluated when selecting a DAS. SCADA systems are designed primarily for instant response to control and conditions. Simultaneous long-term data storage is dependent upon hardware and software that are not standard or widely used by the utility industry. However, utility applications of PV using SCADA may take advantage of existing components, spare parts, and personnel trained in the installation, operation, and repair of these systems. 
Section 3

\section{RECOMMENDED MEASUREMENTS}

This section discusses the advantages and disadvantages of measuring various parameters under three monitoring scenarios: minimal DAS, basic DAS, and support of remote operation. To illustrate how these parameters apply to actual PV systems, two example data formats used by PVUSA are described.

\section{MINIMAL DAS}

If the objective is simply to track energy production and gross system performance, the system output may be monitored by one or two standard energy revenue meters. A second meter may be needed if the system requires significant standby power or if it is required by the governing utility. Some inverters may produce significant energy in harmonics that dissipate quickly in the power grid; in such cases the chosen meter must be insensitive to these harmonics if it is to reflect actual utility revenue.

As a simple operational check, periodic readings from the energy meter may be compared to expected energy production. The expected energy production can be either derived from system ratings and typical CFs based on normal weather patterns or more accurately estimated using actual data from nearby weather stations. There is a difference in accuracy because short-term (i.e., actual) average and long-term (i.e., normal) average solar radiation data can differ by as much as $50 \%$ even for "short" periods of a month or longer. Using actual solar radiation and temperature data, the expected energy can be estimated to well within $15 \%$, with the remaining uncertainty attributable to other unmeasured effects, such as system degradation, soiling, tare losses, etc. Consequently, the "minimal DAS" method of using a meter for performance measurements is only useful for detecting major system failures.

\section{BASIC DAS}

If optimization of system performance is a medium or high priority, additional parameters beyond energy output will be needed. POA irradiance, real ac output power, dc voltage and current, and module back temperature or ambient temperature form a basic set of measurements suitable for most performance evaluation needs.

The amount of sunlight available to a PV array varies greatly with array orientation and location. Not only is a given amount of a beam of sunlight spread over more or less area as the incidence angle between the sun and the PV array varies, but the amount of received diffuse light from the sky and reflected light from the ground vary as the orientation varies. Weather microclimates and ground reflectance (albedo) can also introduce significant variations in available irradiant energy between nearby locations. For these 
reasons, measurement of the actual irradiance incident on the array (POA irradiance) is necessary to improve estimates of fuel availability for the PV power plant.

Since irradiance is an instantaneous quantity, the option to measure the corresponding system output power rather than energy should be considered. While estimation of the power could be performed by differentiating the energy, in practice the energy is measured in quantified increments that can be large enough to make this procedure inaccurate over short time periods. However, energy can be accurately computed from power data. For these reasons, the power measurement is recommended over the energy measurement for the minimum measurement set.

To distinguish between array and PCU performance, dc power must be measured. PVUSA recommends the measurement of $\mathrm{dc}$ current and voltage to obtain dc power because the value they individually provide for troubleshooting PV array problems is well worth the cost of the additional information channels.

Note that some systems may be configured with multiple PV array power connections or multiple inverters. In such cases, as many dc bus voltages and currents should be measured as necessary to identify the total dc power. PVUSA has had poor results using analog dc power transducers, specifically because of poor thermal stability and calibration drift characteristics; instead, separate measurements of voltage and current needed to compute the power are recommended. In addition, when the arrays are connected in a bipolar, center-grounded configuration with balanced positive and negative outputs, separate measurement of the positive and negative pole voltages and any resulting voltage imbalance can provide an effective way to identify array problems.

Finally, measurement of the module back temperature allows computation of the PI. Cell temperature can be estimated using irradiance, ambient temperature, wind speed, and a thermal model of the PV array. In practice this technique may not be as accurate as measurement of the module back temperature. However, a poorly installed thermal sensor may misrepresent the array temperature.

These five measurements form the recommended basic measurement set. These measurements are summarized in Table 3-1, along with the performance measures that can be derived from them. All of the performance measures described in Section 2 can be computed from these basic measurements. Table 3-2 summarizes how these performance measures may be used to evaluate PV system performance. 
Table 3.1

Recommended Basic Measurement Set

\begin{tabular}{||l|l|l||}
\hline Parameter & Units & Derived Performance Measure \\
\hline Plane-of-array irradiance & $\mathrm{W} / \mathrm{m}^{2}$ & $\begin{array}{l}\text { Input power and energy, array and system } \\
\text { efficiency, performance index }\end{array}$ \\
\hline Real ac power & $\mathrm{kWac}$ & $\begin{array}{l}\text { Peak output power, output energy, system } \\
\text { availability, capacity factor, PCU and } \\
\text { system efficiency, performance index }\end{array}$ \\
\hline Array dc bus voltages & $\mathrm{Vdc}$ & $\begin{array}{l}\text { dc power and energy, array efficiency, } \\
\text { voltage imbalance }\end{array}$ \\
\hline Array dc bus currents & Adc & $\begin{array}{l}\text { dc power and energy, array efficiency, } \\
\text { current imbalance }\end{array}$ \\
\hline Module back temperature & ${ }^{\circ} \mathrm{C}$ & Performance index \\
\hline
\end{tabular}

Table 3-2

System Performance Measures Available in Basic DAS

\begin{tabular}{|c|c|c|c|}
\hline $\begin{array}{l}\text { Performance } \\
\text { Measure }\end{array}$ & Indicates & Typical Range ${ }^{1}$ & Used to Evaluate \\
\hline $\begin{array}{l}\text { Input power and } \\
\text { energy }\end{array}$ & Available fuel & $\begin{array}{l}0-1,200 \mathrm{~W} / \mathrm{m}^{2} \text { or } \\
100-250 \mathrm{kWh} / \mathrm{m}^{2} \\
\text { per month }\end{array}$ & $\begin{array}{l}\text { Expected output power and } \\
\text { energy }\end{array}$ \\
\hline ac energy & Energy production & $\begin{array}{l}\text { Accumulates with } \\
\text { rollover period } \\
\text { longer than } \\
\text { measurement } \\
\text { interval }\end{array}$ & Average efficiency \\
\hline $\begin{array}{l}\text { Efficiency of } \\
\text { array, PCU and } \\
\text { system }\end{array}$ & Fuel utilization & $\begin{array}{l}2-15 \% \text { for array, } \\
85-95 \% \text { for PCU }\end{array}$ & $\begin{array}{l}\text { Array, PCU, and system } \\
\text { effectiveness; possible } \\
\text { degradation }\end{array}$ \\
\hline $\begin{array}{l}\text { de voltage } \\
\text { imbalance }\end{array}$ & $\begin{array}{l}\text { Array voltage } \\
\text { asymmetry }\end{array}$ & $3 \%$ & $\begin{array}{l}\text { Module problems or partial } \\
\text { array shading at greater than } \\
5 \%\end{array}$ \\
\hline $\begin{array}{l}\text { dc current } \\
\text { imbalance }\end{array}$ & Ground fault & Less than $1 \mathrm{~A}$ & $\begin{array}{l}\text { Alternate current path, ground } \\
\text { fault, or other failure }\end{array}$ \\
\hline $\begin{array}{l}\text { System } \\
\text { availability }\end{array}$ & $\begin{array}{l}\text { Frequency of } \\
\text { breakdowns }\end{array}$ & $75-85 \%$ & System reliability \\
\hline Capacity factor & $\begin{array}{l}\text { Ratio of actual to } \\
\text { rated output }\end{array}$ & $15-30 \%$ & System energy production \\
\hline $\begin{array}{l}\text { Performance } \\
\text { index }\end{array}$ & $\begin{array}{l}\text { Ratio of actual to } \\
\text { expected output }\end{array}$ & $85-95 \%$ & Overall system health \\
\hline
\end{tabular}

\footnotetext{
'These are typical, not extreme, ranges.
} 


\section{REMOTE OPERATION DAS}

If the system requires remote operation, a broader range of status signals must be provided by the DAS. Selection of which signals should be monitored and how they should be interpreted in general depends on the design of the PCU and the preference of the dispatch operator.

To support creation of simplified status displays, generic status signals should be included to indicate both when the PCU is on and when the PCU self-diagnostics indicate any conditions requiring attention. These generic signals can be generated in software if enough detailed status is acquired, or they may be generated in hardware (by the PCU) to minimize status signal channel requirements.

If the DAS is to support remote restart after trouble shutdown, detailed status signals should be provided so the remote operator can distinguish among different types of faults. This capability is desirable when known operating conditions create temporary conditions that the PCU cannot distinguish from serious faults. Such conditions might include overheating during particularly hot weather, or overcurrent conditions produced by abnormally high irradiance from cloud-reflected sunlight in partly cloudy skies (sometimes referred to as cloud enhancement). Comparison of PCU status during error shutdown with known environmental conditions will allow the operator to decide whether the system can be safely restarted.

\section{EXAMPLE DATA STORAGE FORMATS}

To illustrate how the above guidelines apply to real PV systems, two example data formats from the PVUSA project are presented. Both of these formats include somewhat more than the basic data set.

\section{Simple System Data Format}

As an example of the kinds of data collected for a fairly simple PV system, Table 3-3 presents the contents of each line (record) of data stored for an EMT system at PVUSA. Since each datalogger can produce various types of records (e.g., sampled at different rates or containing different parameters), the first field in each record is a format identification (ID) number that can be used to distinguish among various record types. This value would normally be constant for all records containing the format described in Table 3-3. In addition, since different dataloggers may produce the same data format, a datalogger ID number field is included to identify which datalogger collected the data. 
Table 3-3

Typical PVUSA EMT System Data File Format

\begin{tabular}{|c|c|}
\hline $\begin{array}{c}\text { Field } \\
\text { Number }\end{array}$ & Description of Field \\
\hline 1 & Format ID number \\
\hline 2 & \begin{tabular}{|l|} 
Datalogger number \\
\end{tabular} \\
\hline 3 & Year (YYYY) \\
\hline 4 & Day number ( 1 Jan $=1 ; 31$ Dec $=365$ or 366 on leap year) \\
\hline 5 & Hour/minutes (HHMM) \\
\hline 6 & Seconds \\
\hline 7 & Array dc bus voltage positive (Vdc) \\
\hline 8 & Array dc bus voltage negative (Vdc) \\
\hline 9 & Array dc bus current positive (Adc) \\
\hline 10 & Array dc bus current negative (Adc) \\
\hline 11 & Array dc bus current neutral (Adc) \\
\hline 12 & Module back temperature -Type T thermocouple (Celsius) \\
\hline 13 & PCU status: 0 is off, 1 is on \\
\hline 14 & PCU error recycle: 1 is recycling (automatic restart) \\
\hline 15 & POA irradiance $\left(\mathrm{W} / \mathrm{m}^{2}\right)$ \\
\hline 16 & PCU error: 1 is error \\
\hline 17 & ac current phase $A\left(A_{\text {rms }}\right)$ \\
\hline 18 & ac current phase $B\left(A_{\text {rms }}\right)$ \\
\hline 19 & ac current phase $C\left(A_{\text {rms }}\right)$ \\
\hline 20 & Real three-phase power $(\mathrm{kW})$ \\
\hline 21 & de power $(\mathrm{kW})$ \\
\hline 22 & Fire/smoke alarm: 1 is alarm \\
\hline 23 & Real energy accumulated for the day ( $\mathrm{kWhac}$ ) \\
\hline
\end{tabular}

The PV arrays in these EMT systems are connected with positive, negative, and neutral leads, so two dc voltages, measured line to neutral, are recorded. In addition, the currents in all three leads are monitored to verify the operation of the ground fault protection circuitry (if it fails to shut down a system with a ground fault, these currents will not add to zero).

Three of the status signals provided by the PCU are recorded to document the operation of the system. These status values are treated as floating 0.0 and 1.0 values, which are averaged to provide an indication of what portion of the interval the signal was active.

For troubleshooting purposes ac current is recorded, but these values have proven to be of minimal value because the averaging interval is too coarse for most purposes. Ac voltage is common to all of the EMT systems and is collected by a separate datalogger. 
Dc power (computed from the dc voltages and currents) is included both because this value is needed so often for real-time evaluations and because a small (greater than $3 \%$ under rapidly changing conditions) error can be introduced when power is later calculated from average voltage and current values.

Cumulative ac energy for the day is recorded as accumulated from pulses received from an energy meter incorporated in the EMT PCU. This signal allows evaluation of calibration and computation differences between standard revenue energy metering data and energy computed from power. Note that since the datalogger must be connected and operational at all times to obtain valid estimates of energy production regardless of which instrument is monitored, there is no inherent reliability benefit in using one rather than the other for remote data collection. However, any nonvolatile accumulator in the revenue meter will generally be more reliable than dataloggers and datalogger communications. Thus, energy production values obtained by monthly meter readings may be more accurate than those obtained through the datalogger.

\section{Complex System Data Format}

As an example of the kinds of data collected for a more complex PV system, Table 3-4 presents the data format for a typical US system. Most of the additional data in this example are included because this particular array has four subarrays and inverters. However, three characteristics of this measurement set are worth noting. First, ac voltage as delivered to the $12-\mathrm{kV}$ line is included. In spite of the low sampling and averaging rate, this information can be useful in identifying brown-out conditions, which PV power

may be used to avoid. Second, two types of power meters were installed on this system: an ac power transducer and a PG\&E standard revenue energy meter (JEM-1) with a power output signal. The power transducer provides a more accurate measure of ac power than the revenue meter but lacks energy accumulation. PG\&E's standard revenue metering devices were included to allow evaluation of the systems using instrumentation that will likely be included in production installations. Third, this PV system is configured in four monopoles, so a single voltage is measured at the input of each inverter. Since there are no bipoles and each of the inverters operates independently at a fixed voltage, the voltage imbalance measure does not apply to this system. 
Table 3-4

Typical PVUSA US System Data File Format

\begin{tabular}{|c|c|}
\hline $\begin{array}{c}\text { Field } \\
\text { Number }\end{array}$ & Description of Field \\
\hline 1 & Format ID number \\
\hline 2 & Datalogger number \\
\hline 3 & Year (YYYY) \\
\hline 4 & Day number ( 1 Jan $=1 ; 31$ Dec $=365$ or 366 on leap year) \\
\hline 5 & Hour/minutes (HHMM) \\
\hline 6 & Seconds \\
\hline 7 & dc voltage for inverter \#1 (V) \\
\hline 8 & dc current for inverter \#1 (A) \\
\hline 9 & dc voltage for inverter \#2 (V) \\
\hline 10 & dc current for inverter $\# 2(\mathrm{~A})$ \\
\hline 11 & dc voltage for inverter \#3 (V) \\
\hline 12 & dc current for inverter \#3 (A) \\
\hline 13 & dc voltage for inverter \#4 (V) \\
\hline 14 & dc current for inverter \#4 (A) \\
\hline 15 & $\begin{array}{l}\text { ac voltage phase } A\left(k V_{r m s}\right) \\
\end{array}$ \\
\hline 16 & ac voltage phase $\mathrm{B}\left(\mathrm{kV}_{\mathrm{rms}}\right)$ \\
\hline 17 & ac voltage phase $C\left(\mathrm{kV}_{\text {rms }}\right)$ \\
\hline 18 & ac current phase $A\left(A_{r m s}\right)$ \\
\hline 19 & ac current phase $B$ ( $\left.A_{\text {rms }}\right)$ \\
\hline 20 & ac current phase $C\left(A_{r m s}\right)$ \\
\hline 21 & System real output power measured by Square D transducer (kW; positive is PV source to utility) \\
\hline 22 & \begin{tabular}{|l} 
System reactive output power measured by Square D transducer (kVAR; positive is leading power factor) \\
\end{tabular} \\
\hline 23 & POA irradiance $\left(\mathrm{W} / \mathrm{m}^{2}\right)$ \\
\hline 24 & Module temperature (C; average of four measurements) \\
\hline 25 & Spare \\
\hline 26 & \begin{tabular}{|l|l|l} 
Spare \\
\end{tabular} \\
\hline 27 & Spare \\
\hline 28 & Spare \\
\hline 29 & PCU "On" status (logical OR of four inverter on statuses) \\
\hline 30 & PCU "Trouble" status (logical OR of four inverter trouble statuses) \\
\hline 31 & System real energy output measured by JEM-1 meter during the 10-minute averaging interval ( $\mathrm{kWh}$ ) \\
\hline 32 & $\begin{array}{l}\text { System leading reactive energy output measured by JEM-1 meter during the } 10 \text {-minute averaging interval } \\
\text { (kVARh) }\end{array}$ \\
\hline 33 & $\begin{array}{l}\text { System lagging reactive energy output measured by JEM- } 1 \text { meter during the } 10 \text {-minute averaging interval } \\
\text { (kVARh) }\end{array}$ \\
\hline 34 & System real energy consumption measured by JEM- 1 meter since midnight $(\mathrm{kWh})$ \\
\hline 35 & System real energy output measured by JEM-1 meter since midnight (tens of $\mathrm{kWhs)}$ \\
\hline 36 & System real output power measured by JEM-1 meter ( $\mathrm{kW}$; positive is PV source to utility) \\
\hline 37 & System reactive output power measured by JEM-1 meter (kVAR; positive is leading power factor) \\
\hline 38 & $\mathrm{dc}$ power for inverter \#1 $(\mathrm{kW})$ \\
\hline 39 & \begin{tabular}{|cc}
$\mathrm{dc}$ power for inverter $\# 2(\mathrm{~kW})$ \\
\end{tabular} \\
\hline 40 & $\mathrm{dc}$ power for inverter \#3 $(\mathrm{kW})$ \\
\hline 41 & dc power for inverter $\# 4(\mathrm{~kW})$ \\
\hline
\end{tabular}




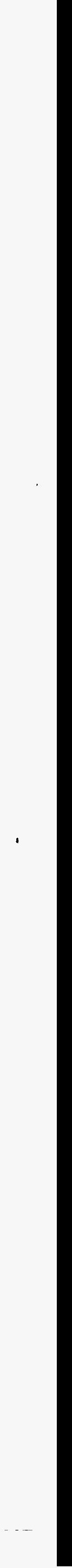




\section{Section 4 \\ MEASUREMENT TECHNIQUES}

This section explains the measurement techniques used at PVUSA. It also describes the instrumentation used in PVUSA's DAS, including sensors, signal-conditioning devices, and dataloggers.

\section{BACKGROUND}

As in most data acquisition, PV system measurements rely on a combination of sensors, signalconditioning devices, and dataloggers or recorders. Sensors (also known as transducers) translate the physical parameter into an electrical analog. Signal-conditioning devices take the sensor output and convert it to a more usable form; for example, they translate an electrical analog into a linear signal proportional to an engineering unit. Eventually the signal is digitized, processed, displayed, and possibly collected by a datalogger or recorder for long-term storage.

\section{SENSORS}

PVUSA systems use a wide range of sensor types, including radiometers, tilt indicators, voltage and current transducers, and thermocouples. Accuracy of sensors ranges from the 0.3 class $(0.25 \%)$ of power transducers to the $3 \%$ or higher for radiation instruments. For almost every sensor type there is a trade-off among accuracy, ease of use, and cost.

\section{Sensors}

Current Shunts. Shunts are simple in-line resistive elements typically used to measure dc current. Resistance is limited to reduce $I^{2} R$ losses and heating. The shunt material is typically a phosphor bronze with additives to reduce the change in resistance with respect to temperature. Meter shunts are inexpensive and widely available. Typical accuracy is quoted as $0.25 \%-5 \%$ with $0.1 \%$ available as an option. In practice, while their output is stable over time, it is difficult to make current measurements with better than $1 \%$ accuracy. Inaccuracies are caused by variations in temperature, contact resistance, and electrical noise. Costs for current shunts range from around $\$ 30$ for $1 \%$ accuracy to $\$ 50$ per unit with $0.25 \%$ accuracy.

In center-grounded bipolar arrays, shunts are usually placed in the high-voltage leg of the circuit under measurement. Such placement results in high common mode voltages ${ }^{1}$ at the datalogger inputs that must be isolated.

\footnotetext{
${ }^{1}$ Even though the shunt is providing a small differential voltage drop (typically $50 \mathrm{mV}$ or $100 \mathrm{mV}$ ) the shunt is located in a circuit that can be tens or hundreds of volts above ground and the datalogger. The datalogger inputs are not typically designed to handle this much common mode voltage.
} 
Hall Effect Devices. The Hall Effect is used to translate current passing through an electric field into a proportional voltage. Limits of accuracy vary but are typically around 5\%. Precision versions to $0.1 \%$ are available, but again $1 \%$ is a practical field limit due to local field disturbances and signal conditioning. Location of the sensor is critical, as changes in ambient electric fields of any type produce a change in the sensor. Therefore, placement of the sensor must be rigid and fixed to allow offset calibration to compensate for the effects of constant electric fields (such as the earth's electric field), and located far enough or shielded from nearby varying fields (such as those produced by inverters) to attenuate their effects to an acceptable level.

Hall Effect sensors are available for many applications. Historically these devices were used for very low frequency (dc) to high frequency ( $3 \mathrm{kHz}$ and up) at a limited accuracy of 5-10\%. Innovations in design and current practice have resulted in wider use of the devices for current measurements. Since the parasitic inductance is small, the limiting factor with respect to frequency is the conditioning circuitry. Sensor prices are $\$ 100-\$ 250$ for $0.25 \%$ and $\$ 300$ and higher for $0.1 \%$ accuracy. For power quality monitoring, PVUSA has purchased a wide-band, split Hall Effect current transformer (CT) with response to $1 \mathrm{MHz}$ and $0.1 \%$ accuracy up to $10 \mathrm{kHz}$ for $\$ 750$.

Voltage Dividers. Resistive voltage dividers sense the voltage of interest by using the relationship of a common current through a pair of resistors in series.

As shown in Figure 4-1, two resistors, $\left(R_{1}+R_{2}\right)$ connected in series across an unknown voltage $\left(V_{\text {unk }}\right)$ will cause a current flow of $i$. The datalogger measures the voltage, $V_{2}$, across $R_{2}$.

$$
\frac{V_{2}}{V_{u n k}}=\frac{R_{2}}{R_{1}+R_{2}}
$$

$$
V_{\text {unk }} \leq V_{\text {unk, } \max }
$$

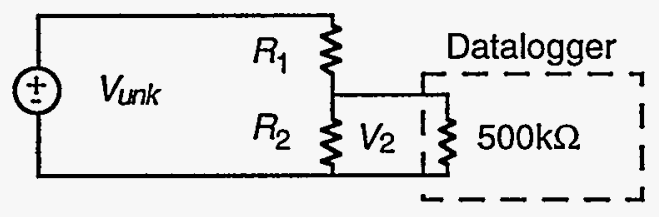

Figure 4-1. Example voltage divider schematic. 
Proper scaling of the resistor pair allows the voltage drop across the resistor $R_{2}$ to be compatible with the datalogger. The following conditions should be considered:

1. For the expected maximum value of $V_{u n k}, V_{2}$ is within the measurement range of the datalogger.

2. $R_{2}$ must be much less than the input impedance of the datalogger to minimize measurement errors. A high datalogger impedance is necessary to ensure that the current flows through $R_{2}$ and that current flow through the datalogger is negligible.

3. The power dissipated across each resistor is within the nominal rating.

4. The current flowing through the voltage divider is small so as to minimize the overall load seen by the $V_{u n k}$ source.

If the effect of the datalogger input impedance is to be kept below $0.5 \%$, then no more than $0.5 \%$ of the current that flows through $R_{1}$ should flow into the datalogger. Requiring $R_{2}$ to be less than or equal to $0.5 \%$ of the datalogger input impedance will ensure this.

Once $R_{2}$ is known, $R_{1}$ must be selected such that

$$
\frac{R_{2}}{R_{1}+R_{2}}=\frac{V_{2, \max }}{V_{u n k, \max }}
$$

Note that large resistor values will minimize both power dissipation and signal loading, but they should also be small enough to maintain sufficient current to ensure the signal is above induced noise.

Voltage dividers cost less than $\$ 10$ for a pair of loose precision resistors to $\$ 50$ for a conformal coated board. Precision resistors are available in $1 \%, 0.5 \%$, and $0.1 \%$ accuracy class with 50 ppm per ${ }^{\circ} \mathrm{C}$ temperature dependency.

\section{AC Sensors}

Current Transformers (CTs). CTs generate a reduced current on the secondary winding that is proportional to the current on the primary winding. Current at high voltage in a primary winding is coupled with a secondary winding at low voltage. This reduced isolated current can then be safely utilized. Frequency response of the device is limited to less than $3 \mathrm{kHz}$ and uncalibrated for frequencies other than the fundamental. Primary to secondary ratios are multiples of 5 with 5 A nominal output for the secondary rating. For example, on a 500-A CT, $500 \mathrm{~A}$ on the primary results in $5 \mathrm{~A}$ on the secondary for a turns ratio of 100:1. PVUSA uses ANSI accuracy class 0.3 CTs. CTs are available in class 1 and 
class 0.3 corresponding to $1 \%$ and $0.25 \%$ accuracy, respectively. Costs are $\$ 30$ and up for a 120 -V-class toroid and $\$ 1000$ and up for a bus-mounted $15-\mathrm{kV}$ device.

Care must be used when working with CTs. Opening an output winding under load can cause the core to saturate and the secondary winding voltage to increase beyond the CT wire insulation rating. Dramatic explosions can result from the combined electrical, magnetic, and thermal energies liberated from the CT. To avoid problems during maintenance, CTs are installed with a multipole test switch that allows the CT to remain shorted whenever instrumentation is disconnected.

Potential Transformers (PTs). Wire-wound potential (voltage) transformers (PTs) use magnetic flux coupling to reduce and isolate voltage sources and match the impedance of source and load. Typically, with the primary winding held at the nominal PT voltage, the secondary will provide $120 \mathrm{~V}$ RMS. PTs are rated up to $120 \%$ of nominal. Typical ratios are 60:1 and 100:1. Most PTs are calibrated at the factory for fundamental frequency $(60 \mathrm{~Hz})$ only. Occasionally specifications will include $40-400 \mathrm{~Hz}$, bracketing the European fundamental of $50 \mathrm{~Hz}$ and military portable power at $400 \mathrm{~Hz}$. Usable signals up to $2-3 \mathrm{kHz}$ can be expected. Above $3 \mathrm{kHz}$, the attenuation is dramatic, making the signal suspect. For power measurements and revenue metering, this attenuation is acceptable since there should be very little power at high frequency. For power quality measurements this limitation may affect results since even low power levels of high-frequency harmonics may cause problems in sensitive equipment. PTs are available in several voltage ratings, turns ratios, and accuracy classes. Prices range from $\$ 50$ for $120-\mathrm{V}$ class 0.3 to $\$ 750-\$ 1,500$ for a $15-\mathrm{kV}$ class 0.3 . PVUSA uses ANSI accuracy class 0.3 PTs.

\section{Meteorological Sensors}

Solar Radiation. Global solar radiation ${ }^{2}$ consists of beam (or direct normal) and diffuse components. Global irradiance is measured with a pyranometer, a device with a $180^{\circ}$ field of view. Direct normal irradiance (DNI) is the component coming directly from the sun, measured by a pyrheliometer, which consists of a sensor placed at the end of a tube that is tracking the sun. Diffuse irradiance is everything but the beam component, measured by a pyranometer with an adjustable shadow band or disk that obscures the DNI. Radiometers (pyranometers and pyrheliometers) estimate incident irradiance by monitoring an absorber for an increase in temperature or by monitoring direct energy conversion to voltage, current, or power. Radiometer output is affected by ambient conditions including temperature, radiation incidence angle, radiation wavelength, and type of sensor surface as well as factors such as age, soiling, and mounting orientation.

\footnotetext{
${ }^{2}$ Radiant power is termed "irradiance," with typical units of W/m $\mathrm{m}^{2}$, while radiant energy is called "insolation" or "irradiation" with units of W-h/m
} 
Pyranometers can be oriented horizontally (common orientation for published data), at a fixed tilt and azimuth angle, tracked in various ways (horizontal single axis, tilted single axis, two axis), or placed in the POA itself (fixed or tracking). POA measurements are somewhat arbitrary. It is difficult at best to get hundreds or thousands of square meters of surface all pointing in exactly the same direction. The problem is exacerbated in systems with multiple independent tracking structures. At PVUSA, site reference instruments in the optimized orientation of the various array types complement POA instruments on each array.

A common physical arrangement for pyranometers is concentric quartz hemispheres over a flat receiver disk within a massive metal housing. The receiver is a metal plate coated with a broad-spectrum, lowemittance absorber material. Attached to the plate is a temperature- or heat-measuring device such as a thermopile. The temperature rise of the receiver above ambient is proportional to the incident irradiance. Alternatively, the short-circuit current of a silicon PV cell can provide a measure of irradiance. Of the two, thermopile pyranometers are sensitive to a broader spectrum and are in general more accurate than silicon-based devices but react rather slowly (1-second time constant). Silicon sensors are inexpensive and respond much more quickly than thermopile devices but are affected by changes in spectral content. Instrument accuracy runs about $2-4 \%$ for secondary reference thermopile devices, and $4-7 \%$ for 1 st class, 2nd class, and silicon devices.

Several factors change the output of pyranometers, making them the least accurate instruments in solar energy measurements. The response of a pyranometer depends on the beam incidence angle. Pyranometers typically maintain $3 \%$ accuracy within about $75^{\circ}$ of normal, and silicon sensors maintain $4 \%$ accuracy within about $50^{\circ}$ of normal. Therefore, the accuracy of irradiance measurements for fixedtilt systems near sunup and sundown is generally poor for these instruments. Some instruments present errors in output due to rapid changes in irradiance, temperature, humidity, age of receiver, azimuth angle (morning calibration differs from afternoon calibration), mounting orientation (device responds differently at $30^{\circ}$ tilt than it does when horizontal), and drift in temperature-compensation circuitry.

Pyrheliometers consist of a thermopile or silicon sensor placed at the end of a collimating tube. Internally, the tube is segmented and blackened to reduce internal reflections. The apparent field of view is approximately $5^{\circ}$, which includes most of the sun, corona, and circumsolar brightening. A tracking device is necessary to maintain the pyrheliometer's orientation normal to the sun. As a result, the incidence angle error inherent in fixed pyranometers does not impact the pyrheliometer. Pyrheliometer calibration uncertainties are thus lower than for pyranometers, often on the order of $2 \%$. However, this accuracy requires that the tracker maintain the pyrheliometer within $\pm 0.25^{\circ}$ of normal to the sun. 
Pyranometers and pyrheliometers range in price from $\$ 1,500$ to $\$ 3,000$ for thermal-based instruments, while silicon devices are $\$ 200-\$ 600$.

Reference cells are PV cells made from the same materials as the PV modules in the system being monitored and packaged in identical encapsulation. They are sometimes used to measure POA irradiance. Because of the material and packaging similarities, variations in spectrum, temperature, incidence angle, and even soiling are, to some extent, taken into account. The output of a reference cell may be a better representation of what the array actually sees than what a clean, broad-spectrum, temperaturecompensated pyranometer would provide. Reference cells are more difficult to calibrate because the spectrum has to be accounted for, and they must be custom made by the module supplier; thus, cost and accuracy will vary. Because of these latter issues, reference cells are not presently used at PVUSA.

Pyranometers and pyrheliometers are available from several manufacturers. Appendix B lists some of the more common instruments, model numbers, and contact information for the various companies.

Temperature. Both ambient air temperature (dry bulb) and cell temperature (or back of module) are measured at PVUSA.

Ambient air temperature is measured by placing the thermal sensor in a radiation shield that minimizes radiative gains and losses. The shield must be aspirated either passively, relying on natural convection ' and wind, or actively, using a motorized fan. Naturally aspirated shields can add up to $2^{\circ} \mathrm{C}$ error over fan-aspirated shields.

Output of a PV device decreases with increasing cell temperature at a rate of $0.3-0.5 \% /{ }^{\circ} \mathrm{C}$ for crystalline silicon and $0.1-0.25 \% /{ }^{\circ} \mathrm{C}$ for amorphous silicon. Cell temperature is therefore a key parameter for assessing array performance. Cell temperature is estimated by attaching a temperature sensor to the back of the module directly behind a PV cell.

Attachment of the sensor to the module is accomplished with a cyano-acrylate, epoxy resin, or siliconebased adhesive compatible with the module back surface material. Choosing an adhesive that has the same coefficient of expansion as the sensor and measured surface will ensure that the sensor remains in contact with the surface measured. For example, typically poor results are obtained from using a thermal epoxy on glass-backed modules, though it works well on Tedlar-backed modules. A silicone-based, selfcuring adhesive works best with glass-backed modules. On concentrator modules, a sensor is usually attached to the back of the heat sink or spreader. 
Difficulties with contact temperature measurements result in field measurement accuracy of $\pm 1^{\circ} \mathrm{C}$. Though absolute sensor accuracy is better, contact resistance between the sensor and the module surface, coupling between the sensor and ambient air, and reference temperature measurement error reduce ultimate accuracy. In addition, there is a temperature difference between the module back and cell of $2-5^{\circ} \mathrm{C}$ for flat plate modules and up to $25^{\circ} \mathrm{C}$ for concentrators.

Table 4-1 presents a comparison of the advantages and disadvantages of the four principal sensor types commonly used for moderately low-temperature applications such as PV.

Table 4-1

Comparison of Temperature Sensors

\begin{tabular}{|c|c|c|c|c|}
\hline & Thermocouple & $\begin{array}{l}\text { Resistive } \\
\text { Thermal } \\
\text { Devices }\end{array}$ & Thermistor & $\begin{array}{c}\text { Integrated Circuit } \\
\text { Sensor }\end{array}$ \\
\hline Advantages & $\begin{array}{l}\text { Simple } \\
\text { Rugged } \\
\text { Inexpensive } \\
\text { Wide variety } \\
\text { Wide } \\
\quad \text { temperature } \\
\quad \text { range } \\
\text { Passive } \\
\end{array}$ & $\begin{array}{l}\text { Most stable } \\
\text { More linear } \\
\text { than thermo- } \\
\text { couples or } \\
\text { thermistors }\end{array}$ & $\begin{array}{l}\text { High output } \\
\text { Fast } \\
\text { Two-wire } \\
\text { resistance } \\
\text { measurement }\end{array}$ & $\begin{array}{l}\text { Most linear } \\
\text { Highest output } \\
\text { Inexpensive }\end{array}$ \\
\hline Disadvantages & $\begin{array}{l}\text { Nonlinear } \\
\text { Low voltage } \\
\text { Reference } \\
\quad \text { required } \\
\text { Least stable } \\
\text { Requires special } \\
\quad \text { wiring }\end{array}$ & $\begin{array}{l}\text { Expensive } \\
\text { Power supply } \\
\text { required } \\
\text { Small change in } \\
\text { resistance } \\
\text { Low absolute } \\
\text { resistance } \\
\text { Self-heating } \\
\text { Active }\end{array}$ & $\begin{array}{l}\text { Nonlinear } \\
\text { Limited } \\
\text { temperature } \\
\text { range } \\
\text { Fragile } \\
\text { Power supply } \\
\text { required } \\
\text { Self-heating } \\
\text { Active } \\
\text { Time constant }\end{array}$ & $\begin{array}{l}\text { Temperatures less than } \\
200^{\circ} \mathrm{C} \\
\text { Power supply required } \\
\text { Slow, self-heating } \\
\text { Limited configurations } \\
\text { Active } \\
\text { Time constant }\end{array}$ \\
\hline
\end{tabular}

1. Thermocouples. The thermocouple (TC) is the simplest sensor, consisting of two dissimilar metals joined at a junction by welding, brazing, or soldering. Simple mechanical junctions are possible for short-term measurements, but corrosion can cause inaccuracies. The junction formed by the two dissimilar metals produces a small voltage $(<20 \mathrm{mV})$ dependent on the temperature difference between the sensing junction and a second (reference) junction typically located at the datalogger. A separate reference temperature measurement and specialized signal conditioning (hardware or software) are necessary to convert the $\mathrm{TC}$ output to a temperature reading.

The thermocouple material type dictates signal level temperature range and accuracy. Thermocouple wire, strip, or rod is manufactured to maintain uniform material and impurities, thereby limiting measurement error due to irregularities. Three grades of thermocouple material are produced that are based on manufacturing tolerances related to 
temperature accuracy: Special Limits of Error (SLE), Standard, and Exterision. The National Institute of Standards and Testing (NIST) publishes tables relating junction voltage to temperature. The tables are developed from wire that meets the SLE criteria. Each manufacturer and production run differs slightly, but the limits ensure compliance with the table specifications. Sensors should be made from standard or SLE material. Standard or extension grade wire can be used to connect the sensor to the signal conditioner and datalogger because it maintains continuity of junction material at splices with minimum cost.

Thermocouples are simple to apply and use despite the restrictions on intermediate connections (splices), reference junctions, and wire type. Maximum extension length is less than $200 \mathrm{ft}$ without amplifiers. One misconception about thermocouples is that terminal blocks made of the thermocouple material are needed for splicing two thermocouple leads together. In reality, the error (voltage) induced by using standard copper terminals is proportional to the temperature difference across the block. Since (1) the terminal is a fairly good thermal conductor, (2) the distance across the terminal is small, and (3) there is usually no external cause for significant temperature gradient across the terminal, the use of standard copper terminal blocks does not produce significant error.

The results obtained by PVUSA using thermocouples have been good, with the exception of thermocouples with sensor or extension wire of less than 20 American Wire Gage (AWG). Fine thermocouple wires easily become strained, corroded, or brittle, resulting in breakage. Breaks in extension wire necessitate the time and expense of pulling new wire. Thermocouples are highly recommended at wire runs under $200 \mathrm{ft}$. Poorly made junctions may be subject to corrosion between metals which could affect calibration. Normally, however, thermocouple failure is characterized by an open-circuit, out-ofrange value.

The conversion accuracy for type $\mathrm{T}$ (Copper-Constantan) special limits of error TCs used at PVUSA is $\pm 0.5^{\circ} \mathrm{C}$. Accuracy is affected by the precision of the device measuring the junction voltage and the translation of the voltage to a temperature. Commercial thermocouples are available at $\$ 10-\$ 50$ and up depending upon the treatment of the connecting wires and configuration of the junction.

2. Resistive Thermal Devices. Resistive thermal devices (RTDs) are based on the principle that resistance increases as temperature increases. The devices are made of expensive, highly pure, low-EMF metals, such as platinum, and require an external power source. Their output is more linear than thermocouples and more accurate. Lead lengths are less of a complication because of the active nature of the devices and because copper wire can be used for extension. At distances of greater than $200 \mathrm{ft}$ an RTD with a current loop transmitter is the best choice. RTDs consist of a resistance bridge with a positive temperature coefficient (change in resistance with temperature). Typical materials are platinum, tungsten, and nickel. Common RTD structures include a bifilar winding on a ceramic bobbin and a metal-glass slurry printed on a ceramic substrate. Bifilar-wound sensors are mechanically fragile and subject to thermal stresses during use (I2R heating) which also cause measurement errors. These errors may change with time and use causing a gradual calibration drift or an infinite RTD resistance when the resistor becomes open-circuit. Printed sensors are more rugged, but often suffer from manufacturing process quality control limitations and nonlinearity. 
RTDs are available in a variety of package styles and configurations. Prices are $\$ 20$ and up for surface-mounted elements. Accuracy is from $\pm 0.7^{\circ} \mathrm{C}$ over the range of -100 $100^{\circ} \mathrm{C}$. RTDs are in use at several PVUSA host sites, but not at Davis.

3. Thermistors. Thermistors are semiconductor versions of RTDs. Their output is typically nonlinear with both negative and positive resistance-versus-temperature coefficients available. Thermistors require a current source for operation. Production tolerances . require characterization of each device to relate temperature to resistance. Thermistors are packaged in a device that is relatively fragile. Device failure, like the RTD, may be gradual or partial resulting in an out-of-calibration result. Thermal capacity is high and desensitizes the device to abrupt temperature changes. Thermistors are available in flat packages for $\$ 10$ at $\pm 0.2^{\circ} \mathrm{C}$ accuracy and $\$ 20$ for $\pm 0.1^{\circ} \mathrm{C}$ accuracy class. Presently, no thermistors are in use at PVUSA.

4. Solid-State Devices. Also called thermal ICs (for integrated circuits), these externally powered devices provide a linear output proportional to temperature. Their narrow measurement range $\left(<200^{\circ} \mathrm{C}\right)$ is not a problem for most PV applications, but there are few configurations available and, as with all active devices, they are subject to selfheating.

Solid-state sensors cost from $\$ 5$ to $\$ 20$ depending on case and precision. Accuracy classes are $\pm 5^{\circ} \mathrm{C}$ (grade J) and $\pm 2.5^{\circ} \mathrm{C}$ (grade $\mathrm{K}$ ). Presently, no solid-state temperature sensors are being used by PVUSA.

Wind Speed. In most situations, wind loading dominates array structural design. Also, wind speed can have a significant impact on module temperature and, therefore, array output.

Common mechanical wind speed sensors use a drag (cup) or lift (propeller) device to turn a shaft, which in turn produces voltage, current, or pulses. Drag and lift sensors are reasonably linear. The lift device has the lowest threshold speed (as low as $0.4 \mathrm{~m} / \mathrm{s}$ ) and is responsive and moderately expensive but must be oriented into the wind. Cup anemometers are inexpensive, but suffer from high static friction and bearing drag. PVUSA uses the lift anemometer at Davis and Kerman.

Highest accuracy and fastest response are obtained with a hot-element anemometer. They are available in omni- and bidirectional configurations. The expense and fragility of the hot-wire sensor prohibit its use in normal atmospheric wind speed environments. In addition, since the device relies on the nonlinear relationship between wind speed and the power needed to maintain the wire at a fixed temperature, either complex signal conditioning or post-processing is needed to obtain results in engineering units. Anemometers are $\$ 50-\$ 250$ for devices accurate to within $\pm 4 \%$ of full scale, and $\$ 500-\$ 700$ for devices with $\pm 1 \%$ accuracy.

Relative Humidity. The amount of water vapor present in atmospheric air can affect the rate at which a module transfers heat to its surroundings, the total irradiance seen by the module, and the spectral content 
of the irradiance. The psychrometric parameters of dry bulb temperature, wet bulb temperature, barometric pressure, relative humidity, absolute humidity, humidity ratio, and dew point temperature are used to describe ambient air conditions. Under reasonably steady state conditions, knowledge of any three of these parameters allows computation of the remaining parameters. Humidity is commonly determined using a sling psychrometer which consists of a pair of close-mounted thermometers, one exposed to ambient air, the other cooled with a water-soaked wick around the thermometer bulb. Forced evaporation of the water (by rapidly swinging the device through the air) reduces the wick to the wet bulb temperature. A separate measurement of barometric pressure (or, for a gross estimate, an assumption of barometric pressure based on altitude) provides the third parameter with which to calculate the remaining parameters.

Keeping the thermometers matched and the wet bulb cooled is difficult to do on a continuous basis. Deionized water, periodic wick change, and frequent cleaning are needed to maintain $0.1 \%$ accuracy.

Electronic sensors are available to measure humidity with greater ease but with reduced accuracy. A capacitive sensor is commonly used to directly measure humidity. A hygroscopic material is used as the capacitor's dielectric. A change in humidity causes a change in capacitance of the device. Signal conditioning integral to the device provides an output voltage that is linearly proportional to humidity. Accuracy of the capacitive sensor is about $\pm 2 \%$. The sensor is sensitive to air pollution, $d c$ voltages, and fingerprints (the oil affects the device's ability to absorb water). Dew-point sensors are also available which measure the temperature of a hygroscopic salt in a forced air stream. PVUSA uses a capacitive device with a field-replaceable sensor.

Rain. The most common method for electronically measuring rainfall, and the method used at PVUSA Davis, is a tipping-bucket rain gauge. A funnel at the top of the device collects rainwater and directs it to one of two buckets at either end of a balance. Rain water is diverted into one bucket until the weight of the water causes the balance to tip. The full bucket empties and rainwater is diverted to the other bucket. Each tip of the balance causes a pulse or switch closure that is equivalent to some amount of rain, usually 0.01 inches. A heater can be supplied to prevent ice buildup and to melt snow (neither of which has been a problem at the Davis site).

The small exit orifice in the funnel tends to collect dirt and is an inviting entrance for insects. Dirt can also accumulate in the buckets and lead to errors. Friction in the beam caused by dirt or corrosion will also affect accuracy. PVUSA's experience is that these devices tend to require vigilance to maintain a clean, properly operating instrument. Costs for these types of devices are around $\$ 300-\$ 500$. 


\section{Miscellaneous Sensors}

Tracker Position. For tracking-type arrays, system output will be lower than expected when the array is not tracking the sun's path accurately. Two types of monitors are available for measuring tracker position. Angular measurement devices (clinometers) measure the position of the array about a tracking axis. Knowing the actual array angle, the tilt-angle error can be computed by comparing the actual and calculated optimal angles. Direct-measurement tracking error monitors measure the incidence angle of the sun's beam component. These monitors have limited range and stability problems that limit their usefulness over time. Both types of devices suffer from calibration inaccuracies due to the array mounting and array flexure.

- Angular Measurement Devices. Three types of angular measurement devices are listed below. The first two use gravity as a reference.

1. Resistive. The most popular tilt-angle sensor, and that used at PVUSA, is the resistive type. A variable resistor with a weighted wiper changes resistance with tilt angle. Resistive devices are available in a wide variety of types and accuracy, but most offer no better than $2^{\circ}$ resolution. Tilt angle is a function of voltage, which is subject to resolution and range restrictions. Design limits often only allow a moderate voltage change between maximum and minimum output voltage, thus not taking full advantage of the datalogger's resolution. Resolution is also limited by the number of windings of the wire on the sliding contact resistor. Thus, both digitization and winding count can result in coarse signal step changes in the recorded position data. Resistive devices cost roughly $\$ 50$ for $\pm 2^{\circ}$ accuracy over a $\pm 50^{\circ}$ range.

2. Capacitive. At least one manufacturer supplies a capacitive sensor based upon fluid in an annulus. A precisely machined sensor body contains a fluid which changes the sensor capacitance as the active fluid fills an annular cavity. On-board signal conditioning converts the ac excitation voltage to a linear dc output which varies with tilt angle. Like the resistive tilt-angle sensor, the capacitive sensor output voltage range is often only a fraction of the supply voltage. Capacitive devices cost around $\$ 200$ for $\pm 0.2^{\circ}$ accuracy with a useful range of $\pm 45^{\circ}$.

3. Shaft Encoders. Devices that encode shaft position with optical, magnetic, laser, or other types of angular position markers are available with accuracies of fractions of a degree. This accuracy is accompanied by a high cost $(\$ 400-\$ 2,000)$ that is not normally justified for application to PV system monitoring.

- Direct Error Measurement Devices. Originally designed for controlling one- or two-axis trackers, these custom-made devices measure the difference in output of two identical PV cells separated by a perpendicular divider or arranged in an inverted "V." The relative output of the two cells provides an indication of tracking error. They are good for small incidence angles, but sensitive to calibration, soiling, irradiance level, differential cell aging, and orientation with respect to the array. Tracking error monitors are custom-made devices; thus cost and accuracy will vary.

Time. All PV measurements should be recorded along with an accurate measurement of time for two reasons. First, correlating data from separate dataloggers on the same site is best done using time stamps, 
and errors in time will result in misalignment of data. Secondly, relative to an earthbound observer, the sun follows a predictable path that is defined by the observer's geographic location (latitude and longitude), the date, and the time of day. Accurate time keeping allows for accurate determination of the sun's position for estimating expected irradiance or cloud cover and for evaluating tracking accuracy.

All PVUSA computers, dataloggers, SCADA equipment, and active PV array trackers have internal realtime clocks that are used to control operation, schedule events, and time-stamp data. While there are special clock cards that can be purchased for computers, all of the PVUSA clocks were included with the equipment at the time of purchase. There is a great deal of variation in clock accuracy and drift among the various pieces of equipment. Personal computer clocks are notoriously bad (easily several minutes a month, in some cases several minutes a week). Section 5 describes some of the methods used to maintain accurate time.

Status Inputs. Status signals are binary (on or off) data usually generated by a mechanical or solid-state switch. The switch is used to enable current flow from a supply (current or voltage) provided by either the source device (i.e., the PCU) or the load device (i.e., the DAS). Electrical isolation is an important characteristic for status connections as it prevents ground loops and voltage level mismatch. In critical applications separate signals may be used to indicate active (high) and inactive (low) states. Installation dictates the signal type, a few of which are described below:

- Mechanical Dry-Contact. The mechanical dry-contact switch relies on a relay contact set that is energized by the status generator. A wetting voltage with current limiting must be supplied to actively monitor the closure. For pulse-counting applications, sample times must allow for debouncing of the closure because the contacts are metallic and spring loaded and will bounce apart one or more times in the first few milliseconds of closure. CSI dataloggers handle de-bouncing automatically.

- Opto-isolated. These switches commonly use light-coupled solid-state relays. These devices consist of an LED and light-sensitive transistor in a common package. Low parts cost, high reliability, and a high degree of isolation make this switch an attractive choice. This type of device requires a stable supply current at a fixed voltage for proper operation of the LED as well as a wetting supply for the transistor.

- Current Loop. Reliable signals over long distances are best made with a current loop. Lead length has little impact as long as the total load capability is not exceeded (typically $10 \mathrm{k} \Omega$ ). Many ranges are possible, with 0-1 mA and 4-20 mA standard. The 4-20-mA range has the advantage that an open current loop will not present a valid signal. The low-level state is defined as $4 \mathrm{~mA}$ and the full-scale reading (FSR) is $20 \mathrm{~mA}$.

- Voltage Source. Voltage source status signals are often preferred for their ease of use. Inactive and active states are represented by $0 \mathrm{~V}$ and FSR, respectively, or by -FSR and +FSR. Care must be taken to ensure that floating grounds, lead resistance, and system faults are not carried by the signal to the datalogger. 


\section{SIGNAL CONDITIONING}

The CSI dataloggers used at PVUSA have adaptive A/D reference voltage with input ranges from $1.5 \mathrm{mV}$ to $5 \mathrm{~V}$. Signals outside this range or with combined differential and common mode voltages more than $5 \mathrm{~V}$ from datalogger ground must be conditioned. Low-level signals are usually conditioned with a simple instrumentation amplifier. This device performs some type of amplification, linearization, or both. When the signal exceeds the datalogger common mode voltage limits, some type of electrical isolation is necessary. Isolation amplifiers typically take an input signal, chop it, pass the chopped signal through a transformer, then rectify and filter the output signal. All of this processing introduces errors in gain, offset, and linearity; however, devices with better than $0.01 \%$ total error are available for low-frequency (slowly changing) signals. For high-level signals where common mode voltage is not a problem, a voltage divider is useful for reducing inputs to an acceptable level.

AC

Energy. Rotating disk meters are an inexpensive and accurate means of metering ac electric energy and can be obtained with pulse output for input to the DAS. Recent additions to metering equipment are digital meters capable of complex measurements for a wide range of power factor and power quality.

For example, the JEM- 1 is a solid-state meter with a published accuracy of $0.25 \%$. In use since the early 1970s, the JEM-1 measures real and reactive power and energy over a wide range of conditions while minimizing the impact of varying voltage, power factor, burden, temperature, frequency, and harmonics. This and similar devices are used by PG\&E and other utilities for revenue metering purposes.

All of the major revenue meter suppliers have introduced electronic meters with many types of metering options. Many of these features are designed to provide data automatically and on demand either through a phone line, SCADA, or dedicated LAN connection. For further information consult Metering Handbook published by the Edison Electric Institute. [2]

Simple analog meters start at less than $\$ 50$ while electronic-type devices with multiple output options cost upwards of $\$ 2,000$. Accuracy class is typically $0.3(0.25 \%)$.

Power, Voltage, Current. Several manufacturers produce utility-class ac transducers. The transducers use inputs from comparable class CTs and PTs and most commonly produce a current loop output proportional to the input. Manufacturers of transducers include Square D, Scientific Columbus, Rochester Instruments, Ohio Semitronics, and Bitronics. PVUSA has used transducers from most of these manufacturers with generally good results. Costs for current and voltage transducers start at around $\$ 150$ while power transducers are about twice that. Accuracy class is typically $0.3(0.25 \%)$. 
Voltage and current transducers compute an RMS level of the PT or CT output and generate a scaled, isolated current loop or voltage. Power transducers measure both PT and CT output and multiply the product of their RMS values by the cosine of the phase angle between the two (displacement power factor). Displacement power factor is measured by comparing peak or zero-crossing phase angle. While this approach is adequate in most utility applications, harmonic content will tend to cause errors.

True RMS power may be computed by passing the product of instantaneous voltage and current through a low pass filter or by measuring the temperature rise in a resistor and scaling the power dissipated. These latter techniques are not generally used in utility applications because of cost and the generally low harmonic content of delivered power.

\section{Amplifiers and Isolators}

Problems related to signal match between sensor and datalogger arise more often than not. Sensors may produce a low-level signal, a common mode voltage outside the datalogger's specifications, a format unrecognizable by the datalogger (e.g., a pulse or parallel port output), or a nonlinear signal.

Several signal-conditioning options exist for each situation described above. Simple amplifications may provide the necessary gain. Isolation devices can accommodate common mode voltage of thousands of volts. Translation circuits integrate, differentiate, sum, linearize, or otherwise convert inputs to compatible signal forms. All of these techniques may be used alone or together to form a signalconditioning package. Commercial signal conditioning is available with ranges of inputs and outputs as well as conversion functions.

Each conditioning function adds noise or offset error. Applied improperly, signal conditioners increase cost and complexity and can result in increased rather than reduced overall error. Minimizing the number of signal conditioners reduces cost and complexity while improving data accuracy. Costs vary depending on accuracy, degree of isolation, and quality. Simple decade-type nonisolated amplifiers can be obtained for well under $\$ 100$. High-accuracy $(0.1 \%)$ amplifiers with $1.5-2.0 \mathrm{kV}$ of isolation can exceed $\$ 300$.

\section{DATALOGGERS}

\section{Campbell Scientific}

For the majority of its data collection tasks, PVUSA uses two dataloggers manufactured by CSI: the CSI $21 \mathrm{X}$ and CR7. Matching the output of utility-type sensors and transducers to datalogger input requirements is, for the most part, straightforward. 
CSI 21X. The CSI $21 \mathrm{X}$ is a self-contained unit with eight differential analog input channels (each configurable to two single-ended inputs), four digital input channels, six digital output channels, and two analog output channels. A self-contained controller performs real-time task initiation, measurement processing, data storage, telecommunications, and keyboard display/interaction.

Accuracies for the $21 \mathrm{X}$ are $0.01 \%$ of FSR for differential inputs and $0.02 \%$ of FSR for single-ended negative and positive inputs.

CSI CR7. The CSI CR7 series datalogger is a mainframe device capable of supporting one or more processor and function modules. Control module functions include real-time task initiation, measurement processing, data storage, telecommunications, and keyboard/display interaction. Input/output (I/O) modules perform all analog and pulse inputs as well as analog and digital outputs. Each I/O module contains its own processor, precision analog interface card, and seven or more slots that can accommodate any combination of $\mathrm{I} / \mathrm{O}$ cards via an std bus and screw-in rails.

Accuracy for the CR7 is $0.04 \%$ of FSR for differential and positive single-ended connections. Negativereferenced single-ended accuracy is $0.06 \%$ of FSR.

Application of the CR7 at Davis allows high channel capacity and multiple I/O configurations. However, the CR7 has an expandable back plane that results in increased overhead for program instructions. CR7 programs run slower, than similar $21 \mathrm{X}$ routines. Additional channels further increase program execution time. If the datalogger is overloaded, situations can arise where the program execution time may exceed the nominal 5 seconds between scans.

\section{Harris/Westronic}

The Kerman grid support system utilizes Harris/Westronic D20 series SCADA equipment. Harris/Westronic equipment uses a central control processor (D20M) and remote terminal units (RTUs) configured to collect analog only (D20A), digital only (D20B and D20S), and both analog and digital signals (D20C). Power to the SCADA is provided by a $48 \mathrm{Vdc}$ battery bank. The master unit and RTUs communicate via a fiber optic network. The processing software in the master unit polls each RTU for available data (report by exception) and stores the latest values in a real-time database. Data are stored as digital representations of the input level ( -2048 to \pm 2047$)$. Conversion to engineering units is done externally by the user. Only the latest, real-time values are stored.

External communication is available through multiple serial ports on the master unit. The ports are independently configured to support a PG\&E-defined software protocol and the Harris protocol 
developed by the manufacturer. Data are telemetered through one port to district operations via an RF link and are provided to an on-site computer through a second port. From the perspective of the central computer, the central control processor may appear to be a series of virtual RTUs whose input data are always available.

\section{Input Voltages}

Input voltages from $-5 \mathrm{~V}$ to $+5 \mathrm{~V}$ are suitable for the CSI $21 \mathrm{X}$ and CR7 dataloggers. Programmable input voltage ranges allow resolution as fine as $0.33 \mu \mathrm{V}$ (5-mV range) for the $21 \mathrm{X}$ and $50 \mathrm{nV}$ (1.5-mV range) for the CR7 without external signal conditioning. Conversion resolution is ensured through a dual-slope analog-to-digital (A/D) converter and programmable conversion ranges. The A/D precision is unique for each datalogger: 16 bits for the CR7 and 14 bits for the $21 \mathrm{X}$. The $21 \mathrm{X}$ and CR7 models provide $16.67 \mathrm{~ms}$ integration intervals to reject $60-\mathrm{Hz}$ noise. The Westronic D20 equipment has \pm 5 - and $\pm 10-\mathrm{V}$ inputs with 12-bit resolution and no inherent noise rejection. Provisions are made on the input cards for shunt resistors to accommodate \pm 1 - or 4-20-mA current signals. External signal conditioning must be used for low-level signals (such as thermocouples and pyranometers).

\section{Sampling Frequency}

In addition to voltage range considerations, the Nyquist sampling theorem, a fundamental theorem of digital sampling, specifies that the sampling frequency chosen should be at least twice the highest significant frequency component in the data. In practice, round-off errors and transient signal analysis requirements suggest a minimum sampling frequency of five times the highest frequency component. Therefore, a key factor for designing a DAS is the frequency content of typical PV system data.

Aside from inverter switching frequencies and the power grid fundamental frequency, the fastestchanging parameters in PV systems are the irradiance and wind speed. In addition, irradiance drives output power; in fact, the array response time is considerably faster (less than $1 \mathrm{~ms}$, limited mostly by circuit inductance) than the typical response time of thermal-type pyranometers ( 3 seconds). Tests performed at the PG\&E Photovoltaic Test Facility in October 1991 under partly cloudy conditions found irradiance varying at more than $0.2 \mathrm{~Hz}$ with slew rates of greater than $200 \mathrm{~W} / \mathrm{m}^{2} / \mathrm{sec}$ for more than a second [3]. These data suggest that sampling rates of $0.4-1 \mathrm{~Hz}(1-2.5$ seconds/sample) would be required to accurately represent power. However, this type of data occurs only under partly cloudy and windy conditions, which are typically periods of low solar energy availability.

For practical reasons PVUSA samples all data at 5-second intervals. While this may result in aliased data during worst-case conditions, it is statistically unlikely to occur. According to a study by Kurokawa [4] 
which analyzed irradiance data statistically, 5-second sampling intervals should maintain accuracy to within $0.1 \%$, with exceptions occurring less than once per year.

\section{Interfaces}

While signal transducers (instrumentation) may be connected to data recording devices using many different techniques, only a few types of interfaces are commonly used in utility environments. Utility power instrumentation typically outputs $\pm 1-\mathrm{mA}$ current loops in an analog fashion while process measurements use 4-20 mA. Such interfaces may be easily converted to a voltage reading by placing a precision shunt resistor in the current loop. Another commonly used interface is the contact closure, in which the instrumentation closes or opens a switch. This interface can be used to transfer either status or pulse information.

By contrast, instrumentation for PV systems (particularly the weather instruments) often relies on nonstandard interfaces optimized for the minimal power consumption needed in remote installations. Table 4-2 presents a summary of the potential interfacing requirements and identifies whether and how either a Harris/Westronic RTU or a CSI datalogger can handle these requirements.

Table 4-2

Potential Instrument Interfacing Requirements

\begin{tabular}{||l|l|l|l||}
\hline \hline Interface & Instrument(s) & Westronic RTU & CSI Datalogger \\
\hline $0-1 \mathrm{~mA}$ & ac power meters & Shunt resistor & Shunt resistor \\
\hline Contact & $\begin{array}{l}\text { ac energy meters, PCU } \\
\text { status }\end{array}$ & Pullup resistor & $\begin{array}{l}\text { Pullup resistor or } \\
\text { custom analog } \\
\text { encoding interface }\end{array}$ \\
\hline $0-50 \mathrm{mV}$ & $\begin{array}{l}\text { Pyranometer, dc } \\
\text { current shunt }\end{array}$ & $\begin{array}{l}\text { External signal } \\
\text { conditioning }\end{array}$ & Direct \\
\hline $\begin{array}{l}0-50 \mathrm{mV} \\
\text { nonlinear }\end{array}$ & Thermocouple & $\begin{array}{l}\text { External signal } \\
\text { conditioning or } \\
\text { reference RTD } \\
\text { and software. }\end{array}$ & Direct \\
\hline Magnetic pulse & Anemometers & $\begin{array}{l}\text { External signal } \\
\text { conditioning }\end{array}$ & Direct \\
\hline
\end{tabular}

Once the signals have been converted to digital form, they become less susceptible to electrical interference (noise). However, the variety and complexity of digital interfaces are even wider than for analog interfaces. The Electron Industries Association (EIA) Recommended Standard (RS)-232, RS-422, RS-485, IEEE-488, IEEE-802, and many other industry standards exist, as well as military standards or proprietary interfaces. 
Fortunately, RS-232 (the serial interface on a conventional PC) is widely used by dataloggers, SCADA RTUs, and various data processing computer systems. ${ }^{3}$ Unfortunately, this standard is designed to be used over short (50-ft) distances between exactly two devices at limited $(9,600$ bits per second or less, at $50 \mathrm{ft}$ ) data transfer rates. Thus, systems with multiple communicating devices or large amounts of data will use an alternative interface. SCADA RTUs often use RS-485 to allow multiple RTUs to be connected via a single pair of wires. CSI dataloggers use custom interfaces to minimize power consumption, with special conversion modules to allow communication through RS-232 interfaces.

To complicate matters further, most digital interfacing standards do not describe the nature of the data being transferred, so a common software protocol must be used among the communicating devices. Various protocols have been defined for SCADA RTUs (e.g., Harris protocol, PG\&E protocol); CSI dataloggers use a custom (proprietary) protocol that is individualized to the particular model of datalogger.

The Harris/Westronic equipment used at the Kerman power plant was purchased with a PG\&E protocol option supported on the primary RS-232 interface port and a Harris protocol option on a second port. The primary interface is connected through a modem and radio link to provide remote real-time operator interface for PG\&E operations personnel. A second port is directly connected to an on-site data collection computer for historical data collection.

The CSI dataloggers used at Davis are connected to the central data collection computer via two types of interface adapters supplied by CSI: short-haul modems (model MD-9) connected on a common coaxial cable and an RS-232 interface converter (model SC-32A). CSI dataloggers located at remote "host" sites are accessed via voice telephone lines using CSI 1,200-baud modems at the datalogger and standard thirdparty modems at the data collection computer.

\section{CAVEATS}

Unfortunately, some system operating conditions defy the most sophisticated error checking. An example of this is the case of an array that is covered with snow or ice, where sufficient light is incident on the array to raise the open-circuit voltage to near operating voltage. Most inverters determine startup using the open-circuit voltage, and when the inverter senses that the array voltage is sufficient, inversion commences. If the array is covered with snow or ice the voltage is high, but no current is available for power conversion and the inverter will remain in standby or startup mode. At the same time, the radiometers are often clear either by solar radiation or operator intervention. The disparity between irradiance and output power will then appear to be a failure within the array or inverter. Determining the

\footnotetext{
${ }^{3}$ RS-232 is also used by some PCUs to allow computer access to measured parameters, status signals, and control.
} 
cause of the failure requires visual inspection to determine inverter and array status. This scenario is but one of many situations that can arise during the evaluation of system data.

With such scenarios in mind, the following caveats should be considered when selecting and using measurement instruments:

\section{Sensors}

- Under some conditions, the common mode voltage can exceed the voltage rating of the equipment, causing erroneous readings or equipment damage. Voltages may rise beyond normal when grounds or neutrals are lifted. Some sensors are sensitive and may be damaged by voltages beyond normal operating range.

- Circuit CTs should never be opened. The effective turns ratio raises the secondary voltage many times above the primary when open-circuited. Wire insulation rating is quickly exceeded, and the CT can explode.

- Current measurements in the field are rarely more accurate than $1 \%$.

- Thermocouple sensors and extension wire should be made of 18 AWG so that the rigors of installation, environment, and age do not cause premature failure.

- RTDs and thermistors are somewhat fragile. The output should be checked periodically for reasonable values. These types of sensors often fail partially.

- Radiometers are delicate instruments which measure a complex resource parameter. Incidence angle, orientation, age, and manufacturer influence operation. The devices should be calibrated annually and monitored carefully for degradation. They should be kept clean and isolated from vibration, and the interior should be kept dry by replacing the dessicant regularly.

\section{Analog Signal Conditioners}

- Isolation amplifiers may introduce their own errors, noise, and offsets.

- The input and output ranges and accuracy should be selected with care. Full-scale accuracy may. be insufficient if low levels of the measured parameter occur frequently.

\section{Dataloggers}

For CSI dataloggers (21X and CR7), the following apply:

- Transducer signal plus common mode voltage is limited to $\pm 5 \mathrm{~V}$.

- Sample integration time for rejecting $60 \mathrm{~Hz}(16.67 \mathrm{~ms})$ is not available on the $21 \mathrm{X}$ 's $\pm 5 \mathrm{~V}$ scale; the $\pm 0.5 \mathrm{~V}$ scale is the largest scale offering this feature. 
- Voltages in excess of $16 \mathrm{~V}$ applied to the front panel can damage the datalogger, requiring factory repair.

For Harris/Westronic equipment (D20), the following apply:

- Standard input ranges are $\pm 10 \mathrm{~V}, \pm 1 \mathrm{~mA}$, or 4-20 mA. External signal conditioning may be required for nonstandard signals such as those provided by thermocouples and pyranometers.

- Only the latest real-time values are stored on the master unit. The lack of local storage means that communications failures between the master unit and the on-site data collection computer or the PG\&E operations network result in lost data.

- The Harris/Westronic system uses report-by-exception. Real-time values are only updated if they have changed by more than a predefined threshold amount. While this reduces transmission times and storage space, it must be accommodated in the data processing scheme.

- Shunt resistors used with current loop signals must be removed from channels reading voltagetype signals, or signal errors will result.

- The D20 equipment's modular design facilitates repair much more readily than the CSI hardware. Processor cards can be replaced without having to remove and reterminate wiring. 
Section 5

\section{CALIBRATION ISSUES}

This section discusses calibration requirements and methods for the instruments used at PVUSA, including sensors, signal-conditioning devices, and dataloggers.

\section{BACKGROUND}

Whether the purpose of PV monitoring equipment is performance evaluation or plant control, proper calibration is essential. Improperly maintained calibrations can lead to misinformed decisions. Erroneously low ac power readings would incorrectly suggest low PCU efficiency and potential PCU problems. Low irradiance readings could mask the existence of an array problem.

To verify calibration, all measurement equipment needs to be tested periodically. Instrument errors outside allowable limits are addressed either by adjustment or replacement of equipment or by changing coefficients in software.

Maintaining calibration can be time-consuming and costly. Occasionally limitations in funding have reduced desired precision. Budgetary considerations have resulted in ac and dc instrumentation in the EMT inverters remaining uncalibrated in the field for more than 2 years. Fortunately, factory calibrations are probably sufficient for 3-5 years. Radiometers degrade with time and must be recalibrated annually to maintain their stated accuracy. PVUSA calibrates all radiometers at Davis on an annual basis. Host sites are informed of the need for annual calibration, but they have not complied on a regular basis.

\section{Methods}

Calibration testing can be performed either by generating and injecting a known signal into the equipment under test or by independently measuring an unknown input signal. The test may consist of a single-point verification or a full-range, multipoint test. Components in the signal path-sensors, signal-conditioning devices, and dataloggers - can be tested individually in the field, or they can be removed and tested in a calibration laboratory. Alternatively, some or all of the components in the path can be calibrated simultaneously in end-to-end fashion. PVUSA uses all of these approaches.

Revenue metering is the utility standard method for determining three-phase generation. A revenue meter uses low-level signals (i.e., $120 \mathrm{Vac}$ and $5 \mathrm{Aac}$ ) from current and voltage transformers to derive a power signal. Power data are integrated and presented as energy, either as a pulse or digital value. The data from the meter are only as accurate as the transformers feeding it. Further, the transformer accuracy is given within limited conditions characteristic of nominal or "normal" conditions such as 
balanced currents at $5 \mathrm{~A}$ and $120 \mathrm{~V}$ and a power factor of 1 at or near the fundamental frequency of 60 $\mathrm{Hz}$. Conversely, metering system accuracy for the class type is quoted for the worst case, usually 0 power factor, $150 \mathrm{~V}, 5 \mathrm{~A}$. Harmonic content over a couple of percent produces unpredictable results. Consult the manufacturer for capabilities of the particular instrument.

Calibration of revenue metering is an established utility procedure with "cookbook"-type processes. Note that, while they are proceduralized, great care must be taken to perform them accurately. Typical procedure at PG\&E is to calibrate or replace the revenue meter annually and test the instrumentation meters every 3-5 years. Solid-state revenue metering may be checked using portable test equipment. Advances in miniaturization have resulted in calibration equipment that connects to the metering test block and simulates voltage and current at specific test conditions: typically, no, partial, and full load at $0,0.5$, and 1 power factor. Should a comparison of the meter reading to the simulated input show that the meter falls outside acceptable values, it is removed and returned to the shop or factory for repair and bench calibration.

Lack of information about instrumentation for PV systems justifies the annual calibration of ac and dc instrumentation that PVUSA performs. The PVUSA experience suggests that robust utility standard instruments and recorders do not require annual calibration. However; periodic verification (singlepoint comparison of value with a secondary standard) of signals is necessary to ensure continuously valid data collection.

PVUSA uses different approaches for different equipment. To the extent possible, end-to-end tests (also called loop tests) in the field are preferred, as they reduce system downtime, allow multiple components to be tested simultaneously, and take into account interactions between different components and between the components and their environment.

An example of an end-to-end test would be array current. A recently calibrated reference current shunt is wired in series with the shunt under test. The signal from the reference shunt is fed into a highaccuracy calibration meter that may have the shunt coefficients entered into software. Under full sun conditions, the PCU is used to vary the array current. (Alternatively, the test is performed several times during the day at different sun intensities to achieve a range of calibration data.) Simultaneous readings from the calibration meter and the datalogger under test are recorded. The resulting data are used to generate new calibration coefficients or verify existing coefficients.

This approach allows the shunt, isolation amplifier, and datalogger to be calibrated simultaneously. However, individual nonlinearity and failures may be obscured by the overall results. PVUSA's 
practice is to verify that the instruments function correctly individually and then perform the loop test. The down side to loop testing using a dynamic source like the PV array is the necessity to synchronize the data from the standard to the end of the loop.

\section{SENSORS}

\section{Sensors}

Calibration of dc voltage, current, and status is relatively straightforward. However, the required voltage and current ranges make field calibration necessary. The availability of precision digital multimeters (DMMs) allows high-accuracy calibration using the PV array. Calibration under varying operating conditions (i.e., with the PCU controlling the array operating point) leads to data that can be difficult to analyze and prone to producing systematic errors. Steady-state data points such as open- and short-circuit conditions are recommended as variations due to dc ripple and peak power tracking can confound the measurements.

Measurement of dc voltage should be a simple matter of connecting a meter with suitable rating to the node of interest. However, high common mode voltage limitations present in some signals may preclude a direct meter connection. Common mode voltage problems are usually circumvented by buffering the output of the voltage divider or current shunt with an isolation amplifier. The isolation amplifier must be linear and properly matched to the signal monitored and the datalogger input. Isolation amplifiers always present additional noise and offset to be accommodated. Noise is exacerbated by using the amplifier at less than the full range. For example, an amplifier with full-scale accuracy of $0.25 \%$ is only $2.5 \%$ accurate if the maximum signal is $10 \%$ of the full-scale value. The maximum signal and full-scale values should be matched for maximum sensor output. For PV systems the cold clear day open-circuit voltage will be highest (about 1.3 to 1.4 times Voc at standard test conditions [STC]). Cloud-enhanced irradiance will push the operating current level to at least 1.25 times short circuit at $1,000 \mathrm{~W} / \mathrm{m}^{2}$. PVUSA has measured irradiance in excess of $1,500 \mathrm{~W} / \mathrm{m}^{2}$ for periods of 30 seconds. Móst dc signals can be calibrated within $\pm 1 \%$ accuracy.

\section{AC Sensors}

Current and Potential Transformers. The PVUSA procedure for ac instrumentation calibration for US-1s was developed over 3 years of US system installations. Prior to installation, instrumentation and protection transformers are bench calibrated to an ANSI standard burden at power factors of 0 and 1 and power levels of 0 to nominal. Calibration is performed at line voltage levels of $480 \mathrm{~V}$ or $12.47 \mathrm{kV}$.

Once characterized, CTs and PTs should not need reverification for their useful life. However, excessive burdens on the transformers can exceed their output capability. The transformer output should be 
periodically verified at normal load conditions to detect device failure, and care must be exercised if additional burdens are added after calibration. Burden/accuracy curves should be requested from manufacturer at time of purchase.

Hall Effect Devices. Hall Effect current sensors rely on the change in an electric field caused by an external magnetic field. Consequently all external magnetic fields are sensed and reflected in the sensor's output. Externalities are minimized if the field is contained in a ferrous toroid (donut) in which the Hall Effect is buried and compensation or signal-conditioning circuitry is utilized.

Calibration of the Hall Effect sensor must be done in situ to account for the external magnetic fields and noise. A range of dc currents are injected in the bus the toroid is monitoring. In practice, generating the hundreds of amperes necessary to simulate the PV array is difficult, and therefore the array itself is often used to supply calibration currents. A primary standard current sensor is installed in the circuit to provide a reference.

\section{Meteorological Sensors}

Radiometers. Radiometers are the least accurate sensor used with PV. Claimed accuracy of $2-4 \%$ for the best thermopile devices may be optimistic at high incidence angles, extremes of temperature, or nonhorizontal use. Inaccuracies in calibration, fabrication, and handling abuse can cause the instrument to be out of tolerance from published specifications. Annual calibration is a must, as both thermopile and silicon devices and their cover materials degrade with time. Orientation of the instrument with respect to the sun (e.g., horizontal, tilted, tracking) can affect calibration results.

Figure 5-1 presents the calibration factor for an Eppley PSP. Notice the effect of azimuth angle (the angle of the sun from due south) on the apparent calibration factor. Calibration of the instrument consists of taking data over a clear day and measuring the output of the instrument, then comparing that value to the reference instrument reading on a point-by-point basis. The plot of calibration factor shows how the instrument output varies from east (left) to west (right). A composite single-point calibration factor is derived from this data set by taking a weighted average of the values near solar noon. 


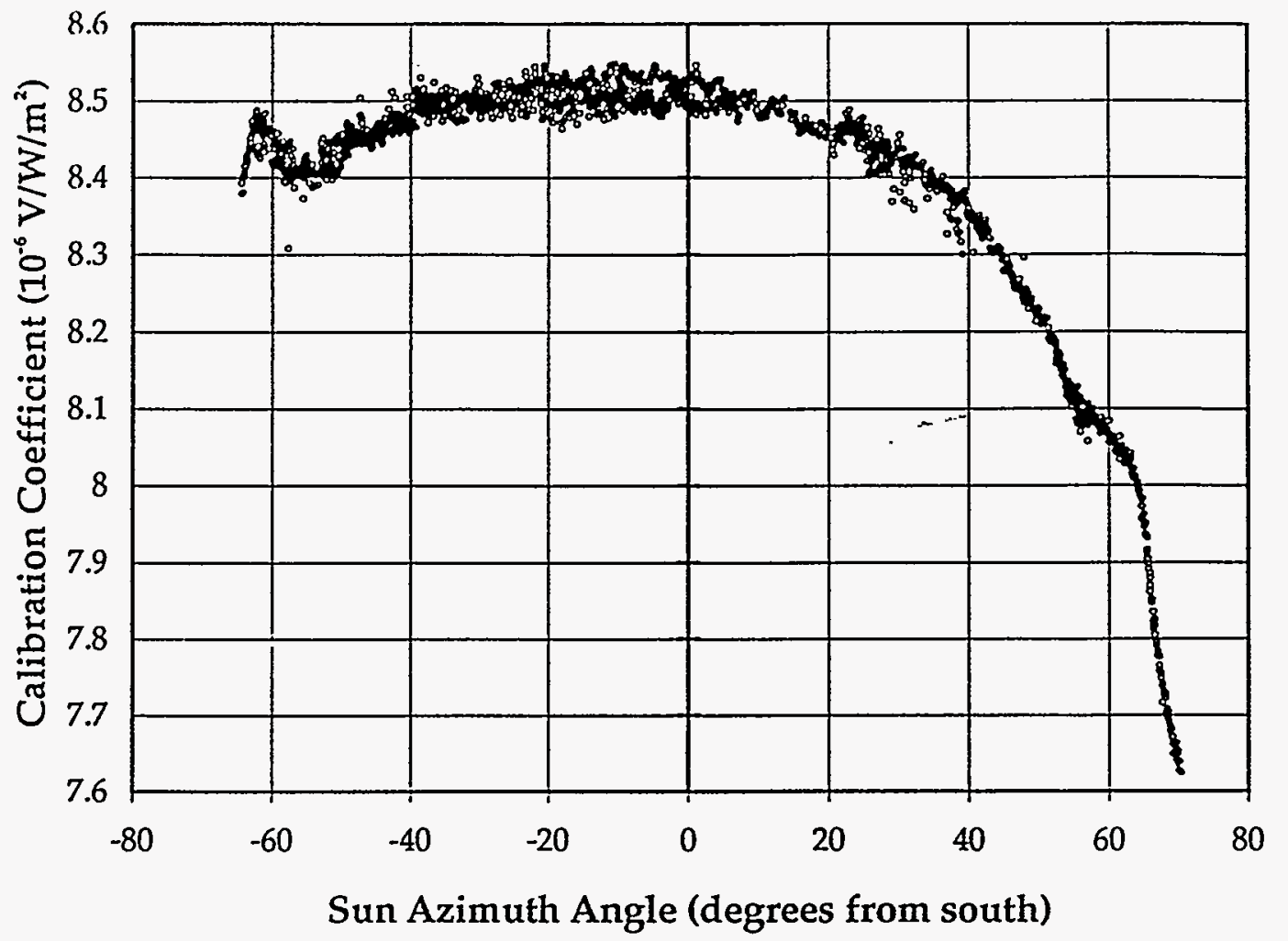

Figure 5-1. Calibration factor versus azimuth angle for precision spectral pyranometer.

Calibration procedures are available from the National Renewable Energy Laboratory (NREL). Recent papers are a good source of information on error and calibration [5]. Calibrating pyranometers requires mounting the instrument in a uniform orientation and knowing the actual radiation falling on the instrument. Naturally, measuring the actual radiation is the difficult part of the calibration. NREL recommends estimating irradiance in the plane of the instrument to be calibrated from the beam and diffuse radiation, using the relation

$$
H_{T O T}=H_{D I R} * \cos \theta+H_{D I F}
$$

Where

$H_{T O T}=$ Total horizontal irradiance, $\mathrm{W} / \mathrm{m}^{2}$

$H_{D I R}=$ Direct (beam) normal irradiance, from reference instrument, $\mathrm{W} / \mathrm{m}^{2}$

$H_{D I F}=$ Diffuse radiation from shaded reference instrument, $\mathrm{W} / \mathrm{m}^{2}$

$\theta=$ Angle of incidence between beam and normal to instrument being calibrated 
At PVUSA radiometers are removed and sent to a suitable agency for calibration. As calibration is typically done outdoors, turnaround time for radiometers can depend on weather and time of year. Presently only one company uses an indoor facility to calibrate instruments. The Eppley PSP, K\&Z CM11 and CM12, and Yankee Environmental TSP1, all broad-spectrum devices, can be calibrated as secondary standard devices and should not be affected by spectral variations. Licor silicoñ pyranometers have a narrower frequency response and poorer off-axis characteristics, making calibration a bit more difficult.

Errors introduced in calibrating radiometers are a result of measurement error, translation error, and changes in instrument response with respect to temperature, irradiance, and incidence angle.

Radiometers are fragile, precision instruments requiring annual calibration. Potential errors caused by instrument degradation or rough handling are known to occur. Regular analysis of pyranometer readings are necessary to ensure that reasonable values are recorded.

Temperature. Temperature measurements for PV systems consist of two types: air measurements and module back measurements.

Ambient air temperature is measured with a probe inside a forced or naturally aspirated radiation shield. Biannual air temperature sensor calibration at PVUSA is verified by the PG\&E meteorological calibration group that uses a mechanically aspirated mercury thermometer accurate to better than $0.25 \%$.

Simple calibration of temperature sensors is also possible with boiling water, corrected for altitude and pressure, and ice baths. Electronic ice points or sand baths allow highly accurate calibrations. Small, slender probes with sufficient lead length may be inserted into thermoelectric ice-point cells; larger sensors may be immersed in ice or heated sand baths. Surface-mounted sensors are usually flat and wide and must be calibrated before installation. Calibration of a surface-mounted sensor is limited to verifying the surface temperature with a second probe. In situ calibration of attached thermal sensors is difficult but may be accomplished with contact sensors to $1^{\circ} \mathrm{C}$.

Calibration of thermocouples is possible by monitoring the junction voltage with respect to the meter voltage or an ice point. Metering must be accurate to less than $4 \mu \mathrm{V}$ to distinguish $0.1^{\circ} \mathrm{C}$. PVUSA uses type $T$ thermocouples, which give the most accurate results over the temperature ranges typically found in PV modules in the field. 
Wind Speed. Wind speed sensors require a minimum of annual calibration. Wind speed is sensed by calibrating a lift or drag-induced rotation to wind velocity. Calibration requires relating the rotational speed to the wind speed in a free stream. This task is best performed by the manufacturer. Two simple field measurements are used to gauge the condition of the anemometer. Bearing drag is monitored during calibration by measuring the frictional torque under rotation. The bearings are replaced when the drag exceeds the manufacturer's recommended limit. Signal output at full scale is measured to determine the proper operation of the signal generator by rotating the device at the full speed rate.

PVUSA follows PG\&E's program of calibrating shaft speed and bearing drag twice a year. The horizontal axis sensor uses lift to induce rotation in the horizontal shaft. If bearings and rotation counters fail partially, the accuracy suffers. By calibrating twice a year, there is a better chance of detecting partial failures.

Relative Humidity. Humidity varies slowly over the day. The simplest device to calibrate humidity is a sling psychrometer. Field calibrations by PG\&E meteorological groups rely on an aspirated wet bulb/dry bulb psychrometer. Replaceable (disposable) humidity sensors are best as the sensing device is subject to soiling and poisoning by airborne pollutants.

Rain. Electronic rain gages use a pivoting bucket to measure precipitation. Rain impacts the funnel of a standard-size collector. The water is channeled into a cup or bucket, which empties when full (approximately $5 \mathrm{ml}$ ). Two buckets are mounted see-saw fashion, and oscillate so one fills when the other is emptying. The emptying action activates a switch or shaft encoder which transmits a pulse to the datalogger. Calibration consists of running a known quantity of water from a pipette into the buckets and recording the number of pulses indicated. Electronic rain gages appear to be less reliable than the other instruments used for meteorological purposes. Buckets must be kept clean to maintain an accurate volume, sensor action must be positive and de-bounced, and obstructions impeding the flow of water must be removed, especially just before, and periodically during, the annual rainy season.

\section{Miscellaneous Sensors}

Tracker Position. Tilt angle measurements can be used to measure the position of tracking structures. This information, in conjunction with knowledge of the structure geometry, time, date, and geographic location, specifies the array position relative to the sun. Comparing the array tilt angle to the sun angle allows an evaluation of tracker performance and system power output.

At Kerman, a resistive device with $1^{\circ}$ resolution is used. Powered by a 5-Vdc external power supply, the device produces a voltage proportional to tilt angle. Supply voltage drift and ripple reduce the absolute 
precision of the device. A capacitive device with $0.2^{\circ}$ accuracy used at Davis and some host sites uses a wide, unregulated range of input (supply) voltage to produce an output that is proportional to tilt angle over the range of $\pm 45^{\circ}$ from horizontal.

Calibration of array tilt angle sensors is performed by measuring the tilt angle with a reference device and comparing reference readings to DAS display. Reference measurements can be made with surveying equipment, a plumb bob and protractor, or an electronic level. PVUSA uses a self-calibrating electronic level with a quoted accuracy of $0.1^{\circ}$. The electronic level is placed on the array structure and the angle is simultaneously recorded on the level and the datalogger. At least 20 readings are recorded for each sensor. The readings are regressed to determine the least-squares, best-fit, linear equation.

Tilt angle sensors are calibrated once every 3 years. Single-point angle verification is performed annually.

Time. Clocks must be calibrated on a regular basis for proper analysis of performance data and for synchronizing data from various dataloggers. Several methods exist to synchronize a personal computer clock to the NIST time standard via modem, radio-frequency link, or network connection through the Internet. CSI software can then be used to set the time on the dataloggers. PVUSA uses a commercial software product called "TIMESET" to automatically call the NIST clock in Washington, D.C., via modem (1,200-baud). TIMESET software accounts for telephone line transmission delays between Washington and the local computer. Weekly synchronization is recommended to support accurate solar position calculations, as datalogger clocks can drift by more than 1 minute per week. Synchronization with the NIST clock is accurate within $400 \mathrm{~ms}$.

Automatic execution of the TIMESET software occurs nightly. PVUSA datalogger clocks within the Pacific time zone are updated using the CSI software, which automatically updates the datalogger clock when a 3-second difference exists. Dataloggers in other time zones are checked weekly and manually set as needed. The R\&D computer at Kerman is updated manually on a weekly basis, first using UNIX-like commands to set the operating, system date and time and then using a system utility to set the hardware clock.

Status Inputs. Relay closures and state change are represented by a changing voltage level from 0 Vdc (low or inactive) to $5 \mathrm{Vdc}$ (high or active). The devices are tested to verify that the signal is within $250 \mathrm{mV}$ of nominal at both low and high states. 


\section{SIGNAL CONDITIONING}

\section{AC Transducers}

Other than PSPs, ac signals are the most difficult to calibrate for PV systems. Calibrations are typically made at fundamental $60-\mathrm{Hz}$ frequency and nominal voltages and with little or no harmonic content. Application of these devices where there is significant harmonic content may not produce results within the specified accuracy.

Transducer calibration ${ }^{1}$ is performed by injecting reference levels of the secondary voltage and current (based on previous PT and CT calibrations and with adjustments for burden) into the transducers. Current, voltage, power, and energy levels are simulated with a precision power supply and recorded with a calibration meter and with the datalogger at several combinations of current, voltage, and power factor. Redundant high-precision metering in parallel with the transducers under test provides additional credibility.

Calibration factors for the datalogger are generated from data recorded in the datalogger and from the reference metering during the signal injection. Linear regression of the data set yields a slope and intercept which are input into the datalogger program. A final round of signals are injected to verify the validity of the calibration factors used by the datalogger. JEM-1 meter calibration factors are directly accounted for by adjusting the instruments to produce the correct number of pulses per $\mathrm{kWh}$.

Ac metering is calibrated annually. PVUSA's experience indicates that a 3-year frequency is 'probably sufficient to maintain $0.25 \%$ accuracy.

\section{Amplifiers/Isolators}

Calibrating amplifiers and isolators is done as part of the loop calibration.

\section{DATALOGGERS}

Three types of dataloggers are used at PVUSA: two models of CSI dataloggers (CR7 and 21X), which use a common technique for calibration, and a utility-standard SCADA RTU which has built-in voltage references with self-calibrating routines.

\section{CSI Dataloggers}

Calibration of the CSI dataloggers is accomplished by adjusting the A/D converter reference voltage while comparing readings from a digital multimeter and the datalogger. A program is loaded into the

\footnotetext{
'Utilities usually have established procedures for calibrating these instruments, as discussed in the Methods section of this chapter.
} 
datalogger to produce a predefined excitation voltage level on one of the analog excitation channels. With a voltmeter with an accuracy of better than $0.5 \mu \mathrm{V}$ at 5 volts, the digital-to-analog (D/A) converter output is monitored at three calibration points of $-4,0$, and $+4 \mathrm{Vdc}$. The reference voltage is adjusted (a variable resistor) so the meter reads correctly to four significant figures. Calibration of a datalogger is not usually necessary, but verification of the voltage levels on the front panel excitation channel should be performed annually to ensure proper operation. Single-point checks performed annually are preferred to ensure valid data. Further details are described in the CSI datalogger manual.

\section{Harris/Westronic RTUs}

SCADA at Kerman is designed for low maintenance. Individual RTUs are located at each major piece of equipment (PCU, switchgear, etc.). The RTU has a microcontroller that runs a self check of the reference voltage through the $A / D$ process. In the event of a random failure the master controller is notified and an alarm set. Field calibration of the voltage reference is verified by a SCADA technician on a 5-year basis. 


\section{Section 6}

\section{DATA PROCESSING AND ANALYSIS TECHNIQUES}

This section describes the data processing portion of the PVUSA DAS and how the performance measures described in Section 2 were computed using it.

\section{EQUIPMENT}

Most data processing in the PVUSA DAS is performed on the three networked IBM-compatible personal computers at the Davis site, Delfina, Godzilla, and Aladdin, shown in Figure 6-1. For purposes of report generation, all computation is performed on Godzilla, but on-the-fly calculations (such as dc power) are computed either in the dataloggers or on Delfina as necessary for real-time display purposes. Delfina collects data from all CSI dataloggers monitored by PVUSA and displays real-time data for all Davis systems. Aladdin collects data from the Kerman R\&D computer and serves as the repository for all raw comma-separated value (CSV) data files. All database operations are performed on Godzilla.

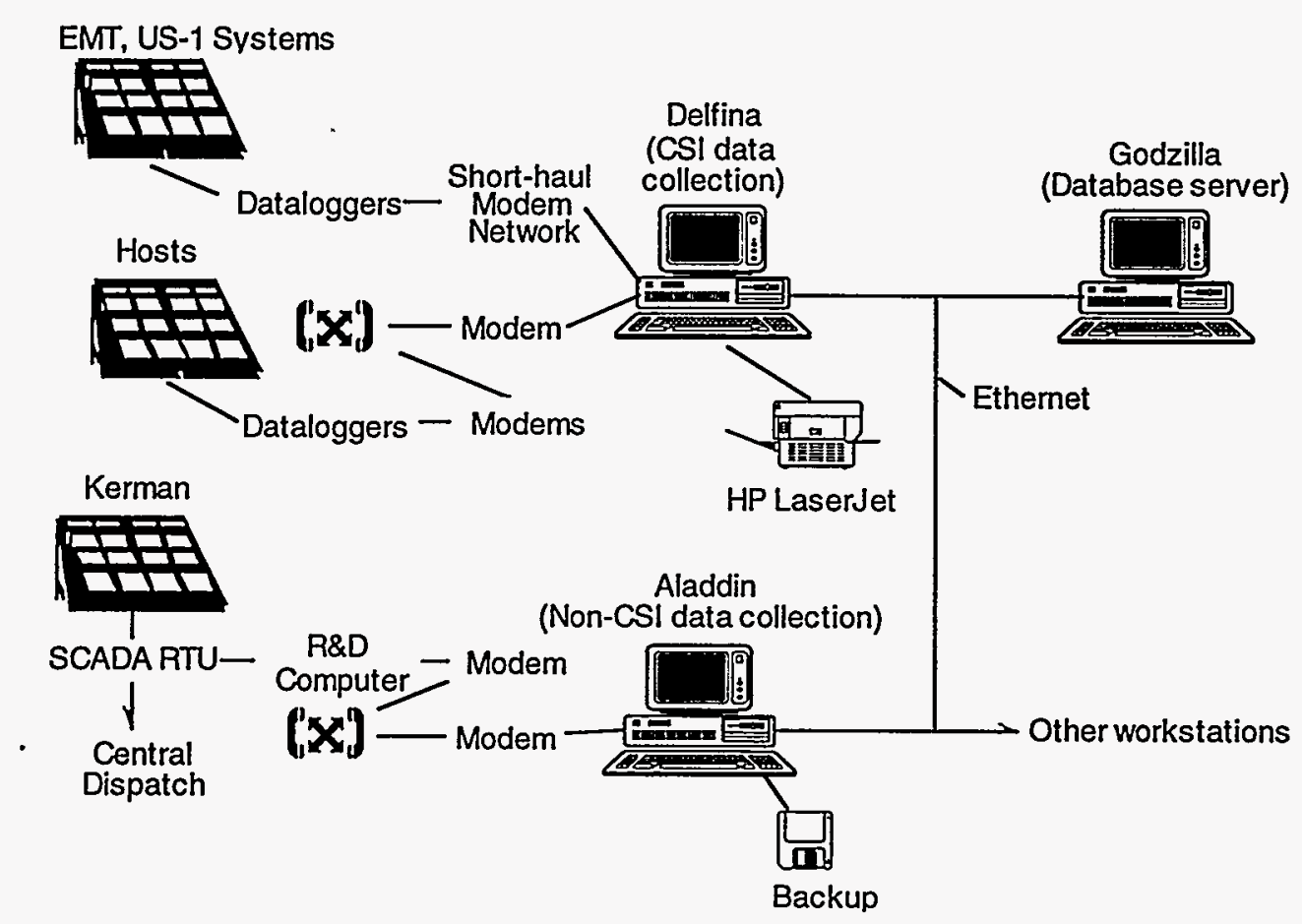

Figure 6-1. PVUSA Davis DAS hardware.

The operating environment on all machines is Microsoft Windows for Workgroups (WFWG) and Microsoft MS-DOS. WFWG provides peer-to-peer networking capability to support distribution of data between the three machines for data redundancy and computation purposes. 
Data are collected at the Davis site from dataloggers located on site, from dataloggers located (remotely) at host sites throughout the United States, and via a computer located at the Kerman site that is dedicated to recording the operation of the system as monitored in real time through standard PG\&E SCADA equipment. The dataloggers located at the Davis site are connected to the central collection computer (Delfina), as shown in Figure 6-1, through a CSI MD-9 network (the short-haul modem network), while remotely located dataloggers are accessed through standard telephone lines via modem. In some cases, there are MD-9 networks connected to the remote modems to allow a single modem to service multiple dataloggers. The Kerman host system is accessed using telephone lines and automated scripts that activate a Kermit file transfer protocol.

CSI's MD-9 is an addressable coaxial transceiver using a carrier frequency of $2 \mathrm{MHz}$. The network is controlled by one MD-9 configured as the network master, which can communicate with up to 254 MD-9s configured as remotes. Commands and data are sent through a serial (RS-232C) connection at 9600 bits-per-second to the MD-9, which modulates the serial data stream and transmits it through the coaxial cable to all of the remotes. The remote which has been activated then demodulates the signal and passes it to the datalogger. Once the desired remote MD-9 has been activated, the communication link is essentially transparent, except that commands and communication must proceed in half-duplex mode (one direction at a time) because the same carrier frequency is used for both data and commands.

The MD-9 network is specifically designed to interface to the CSI dataloggers in locations where available power is limited. The system has the advantages of being power-efficient, simple, and supported by the CSI's telecommunications software. It has the disadvantages of fairly low performance, only allows one central point of access to the data (that is, a local display computer cannot access data while a remote computer dials in to a modem on the network), and requires the use of a relatively bulky type of wire.

A cable TV (CATV) grade of $75 \Omega$ coaxial cable (RG59) runs serially from the CSI MD-9 attached to the control computer in the instrumentation and control (I\&C) building to each MD-9 on the dataloggers in the I\&C building, the EMT1 field, the EMT2 field, back to the I\&C, and finally out to the US field for a cable length of around 3,000 meters. Each MD-9 is connected to the coaxial cable by a "T" connection made with BNC connectors and a female tee. The cable ends are terminated with $75 \Omega$ resistors to minimize interference from end reflections.

CATV cable is usually a copper-clad steel wire of 20 -AWG covered with polyethylene insulation and shielded with aluminum foil and wires. The steel core wire provides maximum strength while providing good conductivity through the copper cladding. PVUSA uses a self-healing, direct burial cable type. 
PVUSA's experience with coaxial cable is that it is subject to damage, signal attenuation, and failure, usually near the connector. A less error-prone option is fiber optic (FO) cable where the communications media is light-based and not as subject to noise, water intrusion, or electrical failure. The Kerman PV power plant uses a FO network to interconnect the SCADA-based data systems (master controller and RTUs). Fiber optics have the advantage of a light-based media that doesn't degrade much with time, has a broad bandwidth, and is less prone to interference. Unfortunately the interface to fiber is not as reliable as the fiber itself. The LED interface and FO connector are susceptible to damage or failure. Partially because of these shortcomings and an early lack of confidence in fiber, Kerman FO cable was installed as a triplex cable consisting of the fiber cable plus two twisted-pair copper cables for backup. Installation of FO cable is similar to normal cable except sidewall pressure (pulling tension) is more critical.

Once installed properly the FO connectors appear to work reliably. The PVUSA experience at Kerman was typical. Initial installation of cable was simple. Connectors were installed by a qualified technician using special tools. Within the year, several connectors degraded and failed. New connectors were quickly installed by the same technician that installed the originals. Subsequent performance has been reliable.

Application of communications network cable requires a thorough knowledge of the characteristics of the media and connectors. Connector installation is an art that requires practice and experience. Proving the connection is an important step towards making a reliable network. The advent of portable test equipment is a critical step toward error free installation of communications systems. Time-domain reflectometers (TDRs) diagnose and locate both actual and potential problems in the cable system. Periodic testing of the network with a TDR is recommended.

\section{SOFTWARE}

It should be noted that two generations of data systems were implemented at the PVUSA Davis site. The first system was developed in 1989 using CSI Model 21X dataloggers, a CSI multiplexing short-haul modem network, and a pair of IBM PC-compatible computers running the Microsoft MS-DOS operating system. This DAS provided the functionality necessary at the time, servicing five EMT systems and including expansion capability sufficient to handle several more EMT systems. It was not designed for the large per-system increase in channel count that occurred as the US systems began to be installed. Limitations of the operating system and custom DAS software became evident as additional PV systems came on-line and memory limits and early programming decisions inhibited expansion. In January 1994, a new DAS program (DataServer, developed for PVUSA) was installed that operates in the Microsoft Windows environment. The new program included a number of features lacking in the original, such as only retrieving real-time data that are needed for the current display, sorting averaged data into separate 
daily files as the data are collected to support backup and data processing in daily increments, and validation of all communications with automatic retry for failed communications.

Figure 6-2 shows a typical real-time display for a single PV system at Davis. This display was created in the Microsoft Excel spreadsheet program using an interapplication communication protocol (Dynamic Data Exchange) to allow the DataServer program to supply the real-time data as needed to any computer on the network. The system being monitored in the example display consists of four subarrays each connected to an inverter. Two different types of ac meters are installed: a Square-D watt transducer, and a JEM-1 watt/watthour meter. Both are displayed for comparison. The displayed energy measurement indicates cumulative energy for the day.

Note that this display includes information on the age of the data being displayed. Since communication failures can prevent data from being updated for hours or even days, data age information was incorporated in the display to avoid misinterpretation.

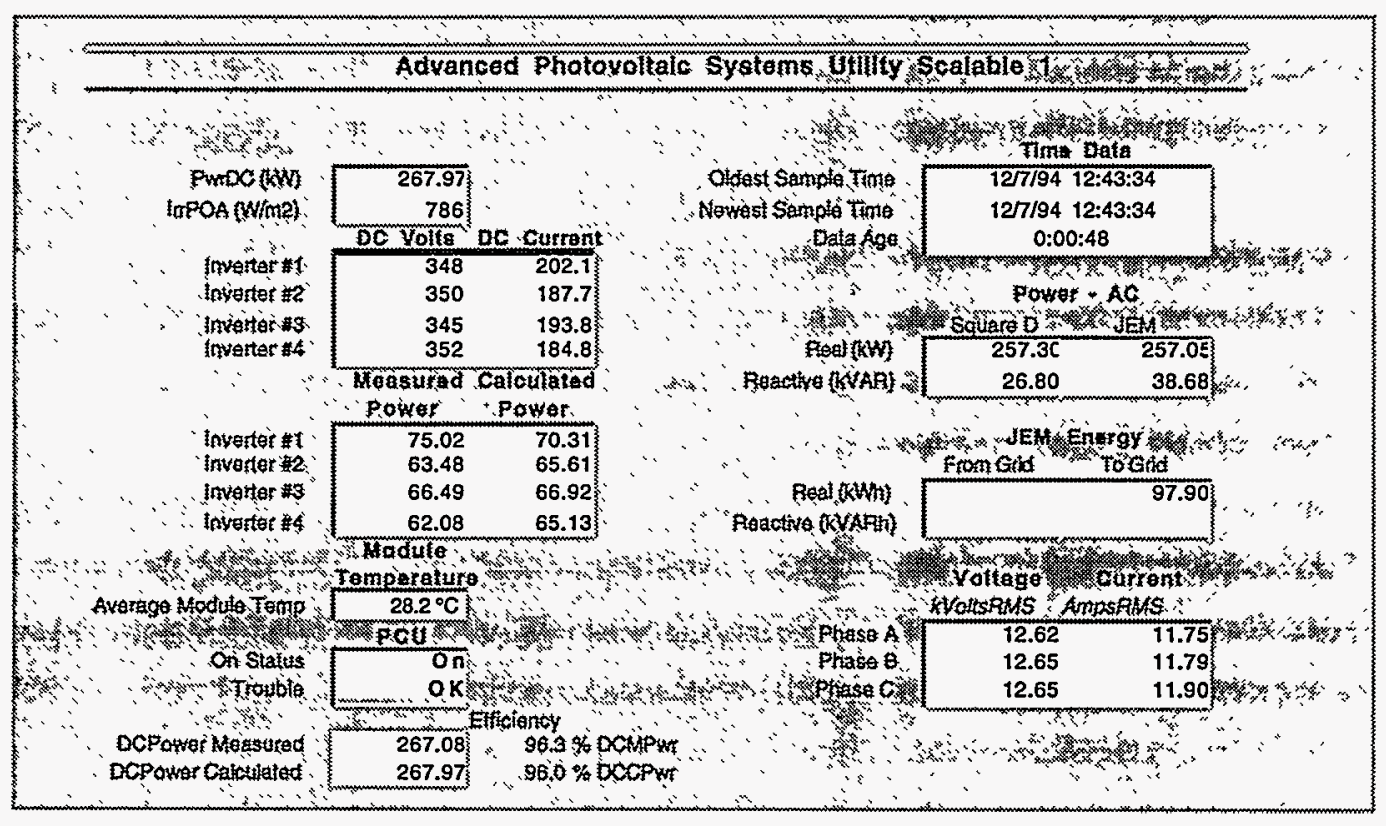

Figure 6-2. Typical single-system real-time display.

The DataServer software stores the data from each datalogger in a series of CSV files, one file per day per system. While this organization simplifies management of data in one-day increments as it is being collected over very long intervals, it does eventually create a multitude of files. This is a problem for 
reporting over long periods because data values must be gathered from many files. It is also a problem when the failures occur in the data collection process because it is cumbersome to identify which data are missing or invalid.

To address the difficulties in managing the large number of CSV files (checking for presence, validity, and archiving), a table-driven companion program to DataServer (DTACHK) performs these operations. Given a simple interval specification (such as " $q$ " to specify the previous calendar quarter), the software will either produce a report on the consistency and completeness of the CSV file sets identified in the input table or archive the files for backup.

To address the difficulties with performance reporting for many differently configured PV systems, a uniform database (described later) was developed. Data processing is primarily performed using a SQL database server (SQLBase by Gupta) augmented with client software developed specifically for PVUSA (using the SQLWindows application development environment). The SQL database provides both fundamental access to and operations on large quantities of data. The client software handles data loading, processing, and retrieval. While the client and server software can run on separate machines via the network, both client and server software are operated on Godzilla to avoid occupying more than one machine during long computations.

Both the database files and the CSV files are archived periodically because each offers different advantages in access to the data. In order to access the data from all systems at the same time, the database approach creates a single database file. This file cannot be allowed to grow indefinitely, so the database must be shut down and backed up by the operator. In addition, extracting the data from the database back to its original CSV organization would be prohibitively time-consuming because the data are so thoroughly reorganized (as described next) in the database. Finally, it is essential for data integrity to maintain a copy of the original unprocessed data (CSV files) for future reference and to reprocess from in case of problems with the database data.

\section{DATA ORGANIZATION}

The organization of the data strongly impacts the data storage requirements, the flexibility of the computational algorithms, and the speed of data processing. The study of how to balance these requirements is an active and extensive area of research in computer science, so the following discussion will essentially be limited to options considered for the PVUSA project. However, some background in how data are typically stored must be discussed before the organization of PVUSA data can be explained. 


\section{Typical Data Storage Methods}

The simplest organization is the flat file database model, which consists of a file (or series of files) containing a series of records, each of which contains several places for data values known as fields. Every record should have exactly the same fields, though the data in each field will generally be different. For example, in a file that contains records with a time field and a voltage field, the time field in the first record might contain 1:00 AM and the voltage field might contain 120, and in the second record the fields might contain 1:10 AM and 0 .

A simple, fairly universal way to store data according to this model is in a CSV file, in which each line represents a record and each field within the record is delineated by commas. By convention, each line must contain the same number of commas. The data file described above could look like:

1:00 AM,120

$1: 10 \mathrm{AM}, 0$

A relational database model is essentially the same as the flat file database model but adds the ability to describe how data in one flat file are related to data in another flat file. A change in nomenclature is also introduced, referring to "tables" instead of files, "rows" instead of records, and "columns" instead of fields. To extend the preceding example, another file might consist of related data collected from another datalogger such as a time field and a status field containing the status of a disconnect switch. The relational model describes how these files may be merged for the purposes of observing whether the disconnect switch was off when the voltage was zero.

A limitation of both of these models is that they assume every record in a file has the same number of fields. This can become a problem when, for example, a new sensor is added to allow some additional monitoring capability. According to the flat file and relational models, the data obtained after the new field is added cannot be stored in the same file as the old data unless the old file is changed to accommodate the new field. In addition, existing computational procedures that access the old file may not be able to properly access the new file.

The object-oriented $(\mathrm{OO})$ database model addresses this problem by requiring that categories (classes) of records (objects) be defined according to which data can be obtained from them. For example, a minimal PV measurement set for a grid-connected application might contain output energy only, while a more completely instrumented measurement set might contain (ac) output energy, ac power, dc power, and irradiance. An $\mathrm{OO}$ database would support the ability to compute statistics on the output energy of all PV systems with a single query. The ability of the $O O$ database to handle variable length records can simplify 
the process of adding data from new PV systems to a database and summarizing their performance along with previously managed PV system data.

\section{PVUSA Data Organization Methods}

For PVUSA, a relational database was selected over an $\mathrm{OO}$ database for three reasons. First, $\mathrm{OO}$ database technology is not as mature as relational database technology, so additional risk would have been involved in using it. Second, the relational database cost less than the $O O$ databases available at the time. Finally, the relational database can be organized to simulate the expandability of the $O O$ database by splitting each specialized record into some general purpose records stored in different tables and merging the general purpose tables as desired.

The PVUSA database was designed to aggregate the data collected from various sources into a single database and produce performance reports on all systems. As initially stored, each data file contained performance data for a single PV system. Host system weather data were also included, but at the Davis site most weather data were recorded separate from the PV system data rather than being recorded redundantly. In addition, the data records collected for each US system varied significantly from the basic format used for the EMT systems. For example, some systems contained multiple subarrays so multiple sets of dc measurements had to be stored in each record.

Structural variations like these generally lead to different performance calculation implementations for each system. Multiple implementations of similar code can be expensive to fix and to expand. However, if the data set can be appropriately reorganized, the same code can be applied to all of it. For example, if each dc power measurement is stored in a separate row, the database can add all of the measurements for a system together to obtain the total dc power for the system. This approach will work whether there is one subarray or eight subarrays. In this case, a set of general purpose tables was formulated that would allow data from all of the PV systems to be entered into the same database tables. Each table represented data from a different kind of major system component (e.g., inverter, subarray, PCU, PV system, power connector). A table-driven data loader was written to automatically split up the as-recorded data records and store them in the appropriate tables in the database. ${ }^{1}$

While this approach succeeded in avoiding the need for special report generation code for each PV system, the limitations of the approach recommend against applying it to single systems or groups of identical systems. First and foremost, the storage required to uniquely identify each general purpose

\footnotetext{
I Some customization for each different data file format is required to handle special data formats, on-the-fly calculations during loading, and record time-stamp recognition.
} 
record so that tables can be merged for computation purposes increased the disk storage by about four times the storage required for specialized tables (a function of the database software). Second, the generalized report computation temporary storage requirements nearly doubled that value. Third, even with the efficient merging techniques available in a relational database, the need to merge the data together slows the computation of performance measures for all systems, no matter how simple or complex. Fourth, for one or two systems of the same type, the data format will rarely need revision, and the potential saving in effort to modify the performance computing code will not be realized.

\section{ALGORITHMS}

While the fundamental algorithms used for generating the standard performance report outputs are simply the equations given in Section 2, in practice three considerations complicate the reporting task. First, elimination of data that are obviously erroneous (out of range) can actually introduce errors into some computations if performed improperly. Second, in some systems multiple measuring devices are monitoring the same information, leading to potential inconsistencies in the results. Third, the goal of reusing computational algorithms on all systems monitored by PVUSA (for reporting consistency) led to the use of a minimal set of measurements for processing, ignoring potentially more appropriate measurements on specific systems.

As a rule, the PVUSA data processing algorithms utilize range checking to avoid including significantly erroneous data in computations. Minor problems such as calibration gain or offset errors cannot be identified using this approach; instead, these types of problems are identified by examining calculated performance measures like efficiency and the PI or by recalibrating or replacing DAS components.

\section{Energy Production}

Energy production for ac power connections can be simply recorded if a watthour meter is installed. However, not all PVUSA data systems include this meter, so in all cases the energy is computed by integrating power data.

Computed values of energy using power data should include all power measurements in the specified interval. Unfortunately, not all of these measurements may be valid, as electrical interference or intermittent sensor connections may introduce out-of-range data points. In practice, invalid data usually occur either infrequently or continuously, so the error introduced by ignoring out-of-range data will be either negligible or so large as to be obvious. 


\section{Efficiency}

Efficiency is computed using two energy values. If one of these values is invalid, no efficiency can be computed. Since energy is computed using power measurements as described previously, any single invalid input or output power measurement will (strictly speaking) invalidate the efficiency computation. However, if corresponding pairs of input and output power measurements are ignored when either one is invalid, then the efficiency is calculated correctly for portions of the total interval, yielding an estimate for the efficiency over the whole interval.

For example, if the dc current sensor was disconnected from midnight until noon one day (and we assume that resulting erroneous measurements are out of range) while the ac power measurements were valid all day, then simply dividing the integrated range-checked ac power by the integrated range-checked dc power for the day might very well yield an efficiency greater than $100 \%$. A better estimate of the actual efficiency would be obtained by dividing the integrated powers over the afternoon only. Of course, the dc energy as computed above would still be incorrectly low, but the sensor problem would no longer be confounding the efficiency measure. This simplifies the analyst's task of identifying the cause of the invalid data after the fact.

\section{System Availability}

System availability for an interval measured in days is computed in two stages. The first stage determines, for each day in a specified interval, how many hours the system was supplying power to the utility, (e.g., when the system output exceeds a threshold value). The second stage uses the site latitude to compute the number of daylight hours per day and divides that into the previously computed number of hours the system was producing power.

The equation used by PVUSA for estimating the day length is

$$
\text { Day Length }=\frac{24}{\pi} \cos ^{-1}\left(-\tan \phi \cdot \tan \left(0.4093 \cdot \sin \left(\frac{2 \pi}{365.24}(284+N)\right)\right)\right)
$$

where $\phi$ is the site latitude and $N$ is the day number of the year ( 1 January $=1,31$ December $=365$ in a non-leap year). Note that all angles are in radians and the result is in hours.

\section{Capacity Factor}

The CF is easily computed according to Equation 2-4 using the energy output computed as described above. 


\section{Performance Index}

The instantaneous PI may be computed from Equation 2-5 without complication, but the average PI described by Equation 2-6 is subject to the multiple dependency problem previously described with regard to efficiency. Average PI should be computed from coincident valid values of output power, POA irradiance, and module temperature. 


\section{CONCLUSIONS AND RECOMMENDATIONS}

Data acquisition and system control functions apply to many of the power systems installed and maintained in the electric utility environment. Since the scale of these power systems may range from $1-\mathrm{kW}$ residential systems to multimegawatt power plants, the character of the appropriate DASs may vary widely. In addition, both the market evolution and institutional standardization of DAS technology affect how data are collected and what data are cost-effective to collect. The DAS for a PV power system, as for other power systems, must be designed to fit the application.

In general, the purpose of the PVUSA project was to install grid-connected PV systems and document how well they work in a utility environment. To this end, the Davis DAS was designed to collect a complete record of performance data both in terms of the variety of measurements and the continuity of the data record. The Kerman DAS was designed to integrate with PG\&E's existing SCADA system to allow remote supervision of the PV system, while providing a variety of measurements and a complete record of performance to characterize the operation of the system. The remaining host system DASs were designed to collect a basic measurement set while operating unattended and autonomously.

Because almost any PV system installed for power production rather than research purposes will likely have different requirements than any of these PVUSA systems, the designers of such a system will have to decide which of the specific conclusions described below are relevant to their case. The two most troublesome areas for the designer of a PV system DAS will be choosing an appropriate minimal set of measurements for their application and producing accurate and correct measures of system performance that avoid misleading the operator, maintenance technician, or analyst. In anticipation of these difficulties, this report has been written to focus on these issues, even though some of the techniques that PVUSA has used may not apply in all cases.

\section{CONCLUSIONS}

1. The choice of parameters to measure for a PV system depends strongly on the purpose of the system. Key characteristics are the system size, intended maintenance schedule, criticality of application, degree of autonomous operation, and whether the system is for research or production. Large systems, critical applications, frequent maintenance, more autonomous operation, and more research-oriented purposes all tend to require that more parameters be measured. These characteristics will likely be strongly interrelated in most applications but may be traded off in some cases. For example, the seemingly burdensome quantity of data to be 
monitored for a large system might allow increased autonomy and self-diagnostic capability at the subsystem level.

2. Costs related to hardware, software, installation, maintenance, data collection, and data processing will be a factor in determining how (and how fully) to monitor a PV system.

3. Signal conditioning will usually be required when monitoring a PV system using a conventional SCADA RTU. In conventional power plants most sensing elements are transducers with current loop interfaces, 5 or $10 \mathrm{Vdc}$, or dry contact closure interfaces. Resistors or a capacitor at the RTU usually provide sufficient signal conditioning to interface to a fixed \pm 5 or \pm 10 Vdc input. On the other hand, thermocouples and most radiometers produce low-level signals that will need to be amplified in order to be sampled without loss of resolution. CSI dataloggers include internal programmable gain and optional 50 - or $60-\mathrm{Hz}$ noise rejection features that reduce the signalconditioning requirements for some signals.

4. The accuracy of some measurements in PV systems is noticeably worse than typical measurement accuracy in conventional power plants. While the nominal accuracy of ac instrumentation (voltage, current, and power) and dc voltage instrumentation is $0.25 \%$ of full scale, dc current is typically $1 \%$, meteorological measurements are $2 \%$, and radiometers are $4 \%$ of full scale. Measurements of tracking PV array structure position have a nominal accuracy of $1^{\circ}$.

Accuracy of the ac instrumentation may be compromised by a number of mechanisms when the corresponding current or voltage total harmonic distortion level is high. PVUSA has not quantified the change in accuracy in the presence of significant harmonic content, but differences in the output of different types of power transducers under such conditions have been noted, implying that some reduction in accuracy occurs.

5. The reliability of the dataloggers used by PVUSA has proven considerably better than that of other components of the DAS. Communication links have been the least reliable component of the system. Telephone lines to some remote sites have high noise levels that challenge the errorhandling capabilities of the communications software. The coaxial connectors used in the MD-9 network at the Davis site have repeatedly developed corrosion failures; this has occurred for both factory- and site-installed connectors. 
In addition, the initial use of cutting-edge PC technology (early 80386-based technology with proprietary "features") in less-than-ideal environmental conditions led to software incompatibilities and several failures of central data collection and processing computers and hard disks. While selection of more rugged and proven computers might have been advisable, the susceptibility of hard disk technology to failure emphasizes the need for appropriate redundant data storage. The use of local storage in the dataloggers and redundant storage of the data on multiple hard disks and backup media has proven quite effective for PVUSA in avoiding data loss.

6. Calibration of the sensors, signal-conditioning devices, and dataloggers is critical to maintaining an accurate data set. In some cases, particularly with radiometers, regular annual calibration is necessary. However, other more-stable equipment may only require single-point verification every few years.

When possible, an end-to-end calibration using an injected signal and the normal measurement system will yield best results. Note that a wide range of input signals and multiple samples should be collected, plotted, and curve-fit to verify that the calibration matches the data and that no outliers are included in the calibration.

7. The chosen operating system and application software has presented a reliability problem for both the Davis central data collection system and the Kerman data collection computer. In both cases, software that was intended primarily for interactive use and administration has been applied to long-term automated operation.

At Davis, the MS-Windows operating environment was used because of its market penetration, including within the PVUSA project. This was expected to lower the costs of performing system administration tasks because project personnel already had these skills within the Windows environment. However, the presence of software bugs in both the operating software and applications used, as well as incompatibilities between certain applications, increased the frequency with which administrative tasks like rebooting machines had to be performed. The lack of isolation between applications (cooperative multitasking between databases, data collection, and data display) and the operating system (MS-Windows with MS-DOS) allows an entire computer to be halted when any failure occurs. The distribution of some tasks to separate machines was required to circumvent these problems (as well as increase system throughput). 
At Kerman, the QNX operating system was used because the selected SCADA data collection software, RealFlex, required it. While lack of familiarity with this operating system hindered its application by PVUSA, the primary maintenance difficulties with this system lay in the administration of, and access to, RealFlex's real-time database, which had to be done remotely because of its location at an unmanned facility. Among these difficulties were problems accessing the data, as well as an absence of any on-line backup and deletion capabilities. These problems resulted in frequently missing data and a risk of system crashes if manual maintenance procedures were neglected.

These software problems are typical of any system for which high reliability is desired. Any software may be expected to become more stable as it is revised, but the supplier's revision schedule may not meet the needs of a particular application. The ability to work around a problem depends on the skills and background of the system integrator and maintainer and access to source code or leverage against the supplier. Availability of skills and leverage are often interrelated: large suppliers supply more software, so skills are more plentiful, while problems with applying that product to particular applications (such as long-term operation or in conjunction with another application) become less important to the supplier. Of course, small suppliers may not have the resources to respond to problems, so no single recommendation applies in all cases. PVUSA has obtained reasonable results using MS-Windows, but maintenance and hardware costs have been higher than expected.

8. DASs are complex systems that can and do suffer partial breakdowns that can affect the quality of acquired data. Incorporating mechanisms for identifying data quality will simplify the task of distinguishing between DAS failures and PV system failures. These mechanisms can include presenting full time-stamp information (including year number) with each real-time measurement, and allowing for unknown (null) values in an archived data set. Time-stamp information can be presented with the data on the real-time display, or used to modify the displayed data (e.g., through color or font style changes) to indicate the relative age of the data.

9. Assuring the quality of archived data is somewhat more difficult than assuring the quality of realtime data, because the conditions that affected the data change with time and are often not recorded. For example, a thermocouple may become detached from the back of a module and therefore record an incorrect module temperature for a period that may be identifiable from the data or from maintenance records. In such a situation, the data collected during that period should be disregarded whether it is within reasonable limits or not. Three options exist for assuring archived data quality: (1) consult a maintenance data table for each data point before using it; 
(2) replace the data with null values, estimates based on other data, or correct values from another source; or (3) store a data quality estimate for each recorded value. The first method is likely to be impractically slow; the second method requires diligent documentation to maintain the ability to trace the origin of the data; and the third method requires additional storage space. PVUSA has not automated any of these solutions, though the technique of manual data replacement from alternate sources has been used in some cases.

Note that data quality evaluation is fundamentally a human endeavor. Automated quality control will not catch or resolve all unanticipated problems, rather it is simply an aid to the analyst. While an ac power meter signal output connected in reverse may result in an obviously out-ofrange reading, the error resulting from the use of the wrong calibration constants in the DAS may be much more subtle. While comparing the ac power with the dc power can be used to help find such subtle errors, unanticipated conditions can confuse the issue even more. For example, if an array is partially covered with snow or ice, the voltage will be high but insufficient current will be available for inverter operation. Meanwhile, the radiometers may be clear, indicating sufficient irradiance and suggesting an inverter failure.

\section{RECOMMENDATIONS}

1. The basic set of measurements recommended by PVUSA includes POA irradiance, module or ambient temperature, dc voltage and current, and ac power or energy. (See Table 3-1.) These measurements are sufficient for general troubleshooting requirements and support computation of the PI. Additional diagnostic status signals-including inverter trouble, transfer trip, ground fault, smoke or fire status, and over/under line voltage - should be included if remote reset capability is desired.

2. For utility-operated systems PVUSA recommends the use of standard SCADA equipment where possible. A utility's existing data collection and processing capabilities, spare parts, and trained maintenance technicians are preferable to new and unfamiliar equipment and maintenance procedures. Care must be taken in interfacing certain low-level and nonlinear signals to equipment intended for high-level, linear voltage and current signals. Inputs should be sampled as fast as the data collection equipment will allow. A maximum sampling interval of 5 seconds per sample is suggested to support inputs such as dc current and ac power, which respond quickly to changes in irradiance. The irradiance measurement itself, measured using a thermopile pyranometer, will react more slowly than the current or power measurements. 
In SCADA systems, the data will often be reported only when it has changed by some minimum amount. The recorded data may be assumed to be constant between updates, so the rate at which the master controller scans the RTUs will effectively be the sampling rate that should be as fast or faster than a 5-second sampling rate.

Note that the decision whether to implement distributed storage (local to data collection) depends on the anticipated reliability of the communication system and the value of historical data to the application. For PV systems that the utility is unfamiliar with, this value may be high until the utility has experience with the value of the system (or the reliability of the communication system!).

3. PVUSA recommends the use of isolation amplifiers on the output of dc voltage dividers and current shunts to protect the datalogger or SCADA RTU input. Large common mode and differential mode voltages may be present on the output of these circuits under fault conditions. Isolation amplifiers will protect against these voltages, which can damage the datalogger or SCADA RTU. However, even the best isolation amplifiers will introduce some additional noise, calibration drift, and expense, so they should only be applied where needed.

4. PVUSA recommends the incorporation of the PI into real-time displays of PV system status. When the irradiance is greater than $250 \mathrm{~W} / \mathrm{m}^{2}$ the PI should generally be greater than 0.9 . When the irradiance is less than $250 \mathrm{~W} / \mathrm{m}^{2}$, the performance model incorporated into the PI equations in Section 2 of this report may not predict power output accurately, so a less stringent test value (e.g., 0.5) should be used. Failure to meet these minimum PI values indicates poor performance and may suggest that the system needs maintenance. Of course, depending on the number of performance variables included in the formulation of the PI, the system may not always have a $\mathrm{PI}$ as high as expected. The PVUSA Davis real-time display incorporates a color-coded indication of the system status that shows whether the system is off with a PCU error (red), off without a PCU error (blue), on with low PI or significant voltage imbalance (yellow), or on with everything okay (green). This status display has proven quite useful in reducing the time required to identify the condition of each system.

5. PVUSA recommends that a sampling rate of less than 10 seconds (preferably 1 second) be used for monitoring PV systems. A 5-second sampling interval should lose less than $0.1 \%$ accuracy due to aliasing with exceptions occurring less than once per year. When calibrating instrumentation, use a few hundred data points for regressions to obtain statistically meaningful results. 
6. For storing historical data on-line, PVUSA recommends the use of a relational database package, as opposed to a flat file database or custom-coded program. Such software packages can greatly simplify the selection of data according to criteria and the merging of data from different sources. These operations are often needed when reviewing historical data for regular operational evaluation and troubleshooting.

7. Data quality control measures should include at least simple bounds checking, with more sophisticated cross-checking of measurements where possible. For example, module temperature must be greater than ambient during daylight hours (due to absorbed irradiance) but equal to or less than ambient at night (due to radiative loss to the sky). Similarly, ac power should be less than dc power. When such conditions are violated, either of the values involved may be incorrect; further tests, possibly including the attention of an analyst or maintenance technician, may be required. To this end, not only should the suspect data be omitted from dependent calculations but the fact that they failed the test should be reported.

8. PV system and DAS maintenance needs to be documented and recorded as thoroughly and regularly as performance data. For systems where the minimal data system is appropriate, maintenance data may simply be necessary to calculate operating costs. In other situations, the evaluation of system performance may be misleading without a thorough understanding of when and how maintenance was performed. Providing maintenance personnel with a single-page, check-box-type form simplifies and standardizes the documentation process and typically results in greater compliance with the documentation requirements. A connection between the maintenance database and the performance database will allow the performance reports to automatically account for data invalidated by the maintenance condition. 

Section 8

\section{REFERENCES}

1. "A New Performance Index for PV System Analysis." Townsend, Timothy U., Charles M. Whitaker, Brian K. Farmer, and Howard J. Wenger. In Proceedings of the First World Conference on Photovoltaic Energy Conversion, Waikoloa, HI, December 1994, pg. 1036.

2. Handbook for Electricity Metering, Ninth Edition, Edison Electric Institute, Washington, DC, 1992.

3. Photovoltaic Module Evaluation Report: 1990-1991 Data from the PG\&E Photovoltaic Test Facility. Whitaker, Charles M., John D. Heinzmann, and Robert M. Candelario. Internal document prepared for Pacific Gas and Electric Company, San Ramon, CA.

4. "Data Sampling Speed Versus Energetic Measurement Errors in Photovoltaic System Monitoring." Kurokawa, Kosuke. In Proceedings of the First World Conference on Photovoltaic Energy Conversion, Waikoloa, HI, December 1994, pg. 726.

5. "Accurate Field Calibration of Pyranometers." 1992. Faiman, D., D. Feuermann, and A. Zemel. Energy, Vol. 49, No. 6, pg. 489. 

Appendix A

GLOSSARY 


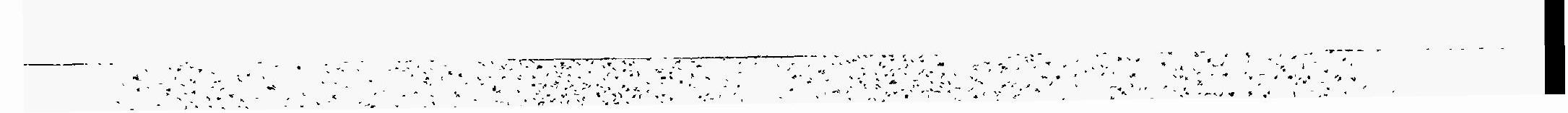




\section{GLOSSARY}

A/D

AWG

Array

BOS

CAO

CF

\section{Clinometer \\ Collimating \\ Tube}

Common

Mode Voltage

Conformal

Coating

CSV

D/A

DAS

Direct Normal Irradiance

DOE

EMT

Fixed Flat

Plate

FSR

GEOS
Analog to digital.

American Wire Gage.

An assembly of modules and panels integrated to form a dc power-producing unit, including the support structure, foundations, tracking system, and other components as required.

Balance-of-system. All equipment and labor, excluding modules, associated with the PV system, such as the support structure, PCU, and utility grid interconnection equipment.

Continuous analog output.

Capacity factor. Ratio of actual ac energy production $(\mathrm{kWh})$ in any time interval divided by the product of the ac rating $(\mathrm{kW})$ and the number of hours in the time interval.

A device for measuring angles of elevation or inclination.

A device that removes all nonparallel components from the light passing through it.

Voltage referenced to earth ground. For differential signals this is the average of the voltages of the positive and negative leads referenced to earth ground.

A dielectric (insulating) material applied in liquid form to electronic circuit boards to create a moisture barrier.

Comma-separated value.

Digital to analog.

Data Acquisition System. A collection of software and hardware used to collect, store, and summarize data.

The irradiance measured normal to the sun, including only direct beam and circumsolar components.

U.S. Department of Energy.

Emerging module technology.

Nonconcentrating solar array on a nontracking structure.

Full-scale reading.

Geosynchronous earth-orbiting satellite. 


\section{GLOSSARY (cont.)}

Insolation Sunlight energy received over a period of time, commonly expressed in kWh per square meter.

Inverter

Equipment that converts dc electricity to ac electricity using power semiconductor components.

Irradiance

Sunlight power measured in watts per square meter. An irradiance of approximately $1,000 \mathrm{~W} / \mathrm{m}^{2}$ is typical near noon on a clear day.

I-V

Measure

Current-voltage.

Measurement

A numerical scale with which values can be compared in magnitude.

A specific value or recorded value with respect to a measure. Often used to refer generically to values corresponding to specific system components.

Module

The smallest complete, environmentally protected, assembly of PV cells, optics, and other components, exclusive of tracking, designed to generate dc power when exposed to sunlight.

Module Back

The temperature of the back of the module.

Temperature

Monopole

Conductors between modules and from modules to the common neutral connection point of a three-wire source circuit. Essentially one half (positive to neutral or negative to neutral) of a three-wire source circuit.

NIST

National Institute of Standards and Testing.

NREL

U.S. National Renewable Energy Laboratory (formerly Solar Energy Research Institute).

O\&M

Operation and maintenance.

Panel

A collection of modules mechanically connected, wired, and designed to provide a field-installable unit.

PCU

Power conditioning unit. A PCU typically contains a dc-to-ac inverter, as well as system protection and control, maximum power-tracking circuits, and a transformer.

PI

Performance index.

POA

Plane of array.

POA

Irradiance

The global irradiance measured in the plane of the array.

PSP

Precision Spectral Pyranometer.

PTC

PVUSA test conditions. Defined as $1,000 \mathrm{~W} / \mathrm{m}^{2} \mathrm{POA}$ irradiance for flat plate modules, $850 \mathrm{~W} / \mathrm{m}^{2}$ direct normal irradiance for concentrators, $20^{\circ} \mathrm{C}$ ambient temperature, and $1 \mathrm{~m} / \mathrm{s}$ wind speed.

PV

Photovoltaic. The direct conversion of sunlight into dc electricity. 


\section{GLOSSARY (cont.)}

PV Cell

Pyranometer, Pyrheliometer

RMS

RTD

RTU

SA

SCADA

SLE

SNL

SSI

STC

Subarray

THD

UPG

US
The basic device that converts sunlight directly into dc electricity.

Instruments that provide a dc signal voltage proportional to the irradiance they are exposed to. Pyranometers respond to global irradiance, and pyrheliometers respond to direct normal irradiance only.

Root mean square. The RMS value of an ac voltage or current waveform is equal to the corresponding dc voltage or current that would dissipate the same power through the same resistive load.

Resistive temperature device.

Remote terminal unit.

System availability.

Supervisory Control and Data Acquisition.

Special Limits of Error.

Sandia National Laboratory.

Siemens Solar Industries, Inc. (formerly ARCO Solar, Inc.).

Standard test conditions. Defined as $1,000 \mathrm{~W} / \mathrm{m}^{2} \mathrm{POA}$ irradiance for flat plate modules, $850 \mathrm{~W} / \mathrm{m}^{2}$ direct normal irradiance for concentrators, $25^{\circ} \mathrm{C}$ or $28^{\circ} \mathrm{C}$ cell temperature, and air mass 1.5 spectrum.

Portion of an array connected to a single unipolar or bipolar dc power connection point.

Total harmonic distortion.

Utility Power Group.

Utility Scale. 


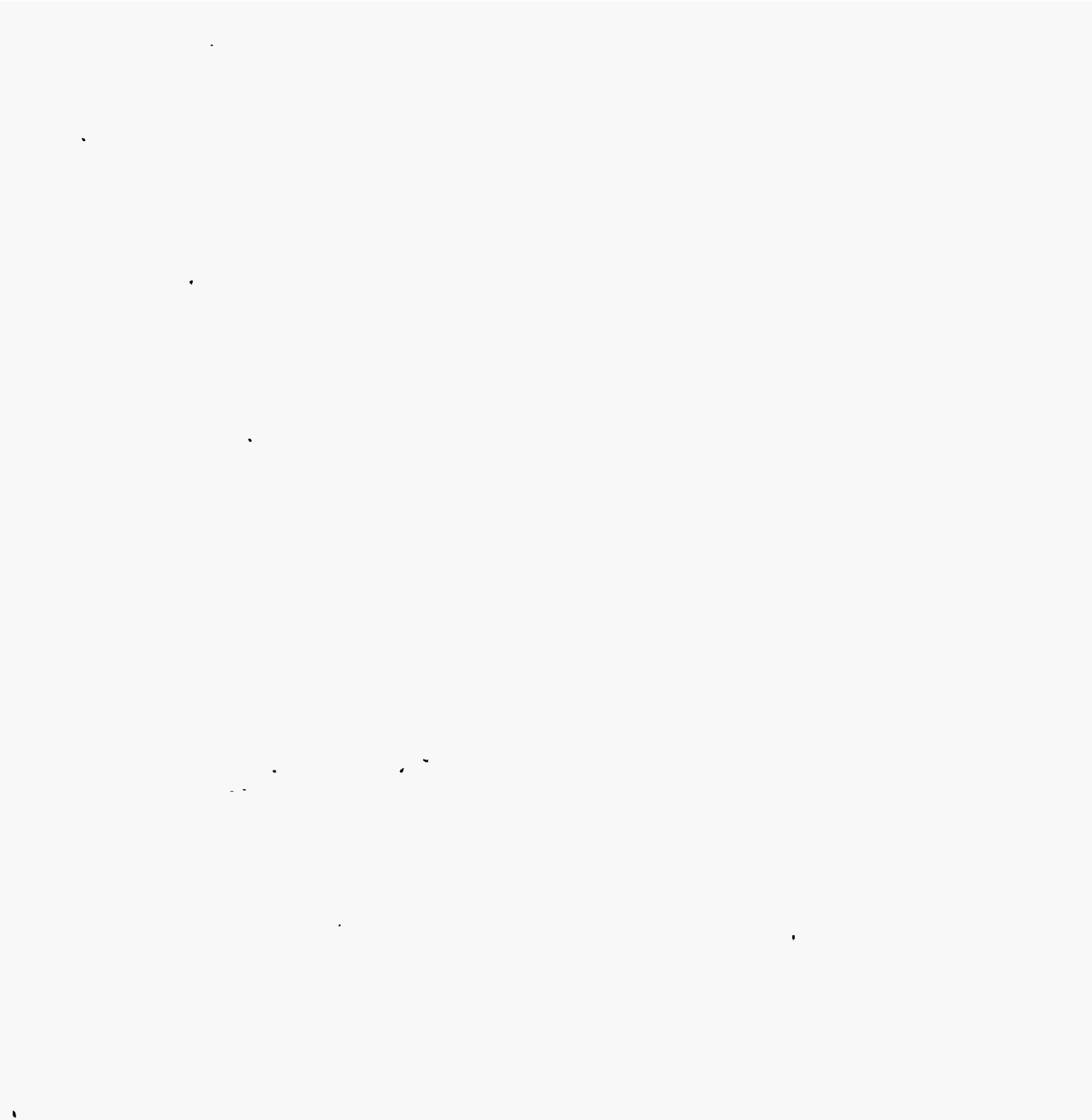


Appendix B

RADIOMETER SUPPLIERS 



\section{Appendix B \\ RADIOMETER SUPPLIERS}

There are two types of radiometers. Broad-spectrum radiometers sense radiation over a broad ultravioletto-infrared frequency range (285-2800 nanometers) by measuring the temperature of a nonselective coating. Narrow-frequency solid-state devices use a photocell or photodiode to capture most of the visible portion of the spectrum (300-1500 nm). This appendix lists both types of radiometers produced by various known manufacturers.

\section{BROAD-SPECTRUM RADIOMETERS \\ THE EPPLEY LABORATORY, INC. 12 Sheffield Avenue \\ Newport, RI 02840 \\ (401) 847-1020 Tel \\ (401) 847-1031 Fax}

The Eppley Laboratory manufactures several types of radiometers, including the Precision Spectral Pyranometer (PSP) and the Normal Incidence Pyrheliometer (NIP):

PSP. The PSP is a heavy, brass-bodied passive sensor. Two concentric ground Shott glass hemispheres cover the receiver, which is a metal disk painted with optical black lacquer in contact with a thermopile. Thermopile output is referenced to ambient temperature through the pyranometer body. This difference is linearized over the ambient temperature range by a parallel compensating thermistor. Care must be taken to keep the body shielded from direct solar gain, which is the purpose of a white metal disk surrounding the glass lenses. The PSP is accurate to a nominal 4\%. Response varies over the field of view both in azimuth and incidence angle of radiation to the instrument. Inaccuracies from orientation and mounting position are likely, resulting in errors around $4 \%$ or more. Output is $8-10 \mu \mathrm{V} / \mathrm{Wm}^{-2}$.

NIP. The NIP collects beam radiation from an area of circumsolar sky about four times larger than the sun. The instrument is a stainless steel tube approximately $1 \mathrm{ft}$ in length. One end of the hermetically sealed tube contains a temperature-compensated, wire-wound spool thermopile coated with optical black lacquer. Solar radiation is transmitted through a quartz window with an aperture of $5.7^{\circ}$. Calibration error of the NIP is $1-2 \%$. Output is $8-10 \mu \mathrm{V} / \mathrm{Wm}^{-2}$. 
Kipp \& Zonen

390 Central Avenue

Bohemia, NY 11716

(516) 589-2885 Tel

(516) 589-2068 Fax

Kipp \& Zonen is an instrument company based in the Netherlands that produces several models of pyranometers, including the CM11 and CM21:

CM11. The CM11 is classified as an ISO 9060 secondary standard. This device uses a 100-thermocouple sensor (thermopile) imprinted on a thick-film substrate. The sensor is housed under $\mathrm{K} 5$ glass domes. Spectral range is $305-2800 \mathrm{~nm}$. Output is $4-7 \mu \mathrm{V} / \mathrm{Wm}^{-2}$.

CM21. The CM21 is the same as the CM11 with improved sensitivity (14-17 $\left.\mu \mathrm{V} / \mathrm{Wm}^{-2}\right)$, impedance, temperature response, nonlinearity, and response time. When fitted with quartz domes the CM31 also has extended spectral response.

\section{Yankee Environmental}

PO Box 746

101 Industrial Boulevard

Turners Falls, MA 01376

(413) 863-0200 Tel

(413) 863-0255 Fax

Yankee Environmental produces two radiometers, the Total Solar Pyranometer (TSP-1) and the Total Solar Radiometer (TSR-1). The latter is a silicon cell radiometer.

TSP-1. The TSP-1 radiometer uses an active thermal sensor, external current excitation, and signal conditioning to produce a linear dc output from 0 to 5 volts. An RTD measures the temperature of the receiver disk. RTD output is highly accurate and linear. Instrument output is rated at $5 \mathrm{Vdc}$ at full scale with $120 \mathrm{Vac}$ input to the signal conditioning power supply.

\section{SILICON CELL RADIOMETERS}

PV cell radiometers use a solid-state device. Radiometers based upon photo cells suffer from narrow frequency response based upon the selection of cell material type, temperature sensitivity, and degradation in output with time. Cosine response and high precision is possible with proper design. Photo cell radiometers are more rugged than thermopile devices. The Licor and Yankee Environmental silicon cell pyranometers are inexpensive alternatives to measure a limited range of visible light. 


\section{Licor Scientific}

4421 Superior Street

P.O. Box 4425

Lincoln, NE 68504

(800) 447-3576, (402) 467-3576 Tel

(402) 467-2819 Fax

Licor Scientific manufactures the LI-200 radiometer:

LI 200S. The silicon cell on the LI $200 \mathrm{~S}$ is mounted in a molded black plastic holder with a molded white translucent plastic plug to protect the cell and provide cosine correction. Output of the device is about 10 $\mu \mathrm{V} / \mathrm{Wm}^{-2}$ with a Licor-calibrated load resistor. Spectral response is $300-1500 \mathrm{~nm}$. Time to respond is essentially instantaneous.

\section{Yankee Environmental \\ PO Box 746 \\ 101 Industrial Boulevard \\ Turners Falls, MA 01376 \\ (413) 863-0200 Tel \\ (413) 863-0255 Fax}

The Yankee model TSR-1 is a solid-state detector mounted in a body similar to the TSP-1. Light is collected and guided to the photo-detector by a Teflon diffuser. The diffuser is designed to collect light over $180^{\circ}$ of the sky dome.

Temperature compensation of the TSR- 1 is provided by a space-qualified thermal regulation servo circuit which maintains the detector at $45^{\circ} \mathrm{C}$. A side benefit of the heated sensor is that it clears dew, ice, and snow quickly. An additional monitor thermistor is available to measure the detector temperature.

Output is 0 to $4 \mathrm{Vdc}\left(2.5 \mathrm{mV} / \mathrm{W} / \mathrm{m}^{-2}\right)$ with an excitation voltage of 11 to $14 \mathrm{Vdc}$. Calibration error is $5 \%$. Spectral response is $300-1500 \mathrm{~nm}$. 
,

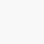

